Prepared in cooperation with the Bureau of Reclamation

\title{
Modeling Hydrodynamics, Water Temperature, and Water Quality in Klamath Straits Drain, Oregon and California, 2012-15
}

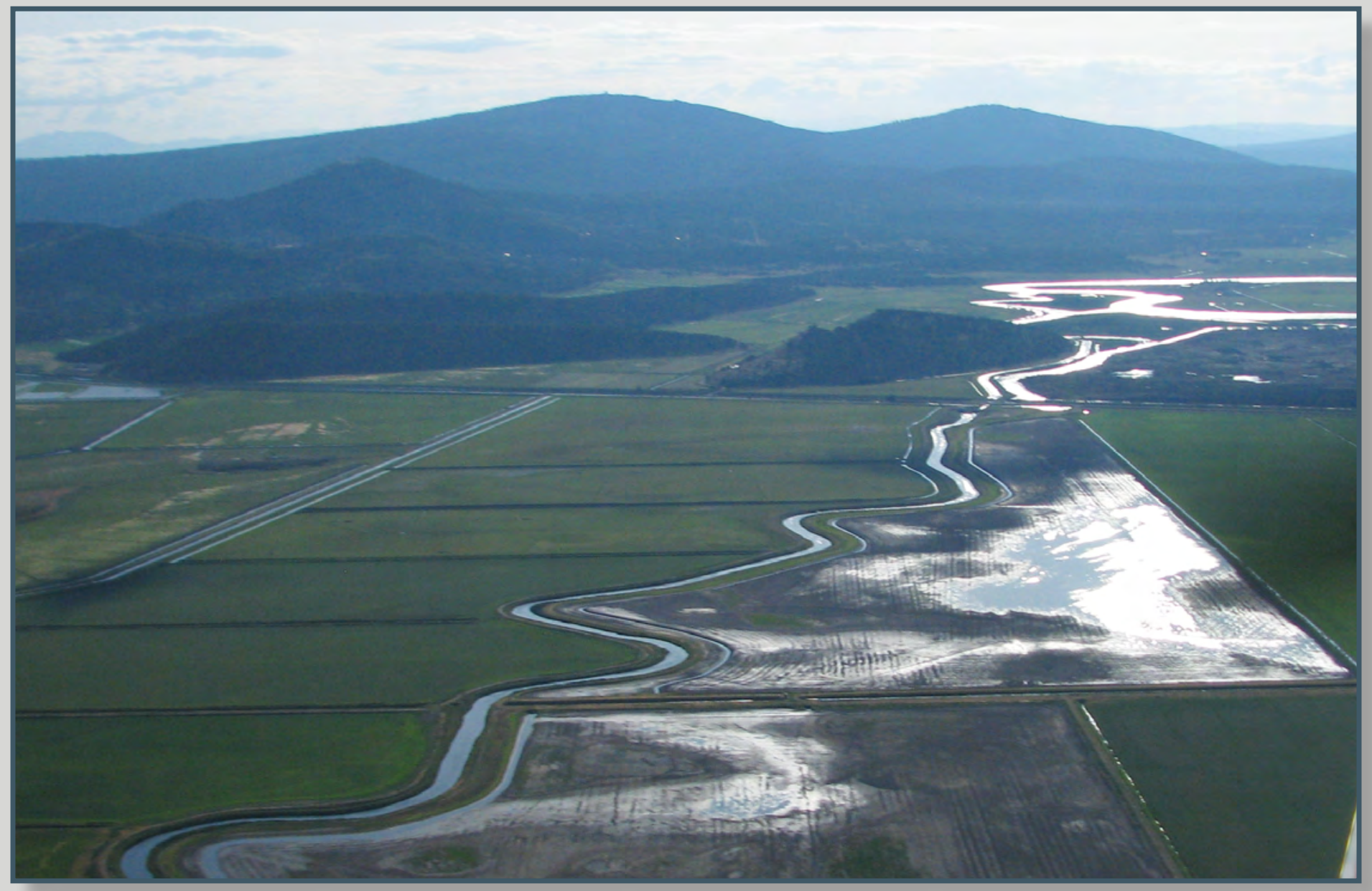

Scientific Investigations Report 2018-5134 
Cover: Photograph showing northern part of Klamath Straits Drain, as seen looking west towards Highway 97 and the F-FF pumps and farther towards the confluence with the Klamath River, Klamath County, Oregon. Photograph by Chauncey Anderson, U.S. Geological Survey.

Back cover: Photograph showing Klamath Straits Drain headworks, as seen from the eastern shore, Siskiyou County, California. Photograph by U.S. Geological Survey. 


\section{Modeling Hydrodynamics, Water Temperature, and Water Quality in Klamath Straits Drain, Oregon and California, 2012-15}

By Annett B. Sullivan and Stewart A. Rounds

Prepared in cooperation with the Bureau of Reclamation

Scientific Investigations Report 2018-5134 


\section{U.S. Department of the Interior \\ RYAN K. ZINKE, Secretary}

\section{U.S. Geological Survey James F. Reilly II, Director}

\section{U.S. Geological Survey, Reston, Virginia: 2018}

For more information on the USGS - the Federal source for science about the Earth, its natural and living resources, natural hazards, and the environment-visit https://www.usgs.gov or call 1-888-ASK-USGS.

For an overview of USGS information products, including maps, imagery, and publications, visit https://store.usgs.gov.

Any use of trade, firm, or product names is for descriptive purposes only and does not imply endorsement by the U.S. Government.

Although this information product, for the most part, is in the public domain, it also may contain copyrighted materials as noted in the text. Permission to reproduce copyrighted items must be secured from the copyright owner.

Suggested citation:

Sullivan, A.B., and Rounds, S.A., 2018, Modeling hydrodynamics, water temperature, and water quality in Klamath Straits Drain, Oregon and California, 2012-15: U.S. Geological Survey Scientific Investigations Report 2018-5134, 30 p., https://doi.org/10.3133/sir20185134.

ISSN 2328-0328 (online) 


\section{Contents}

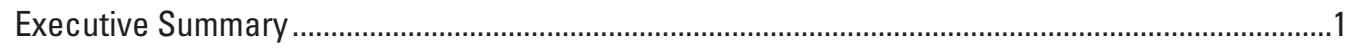

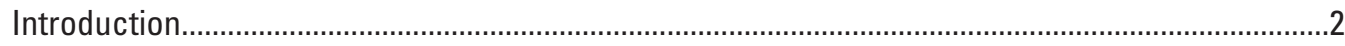

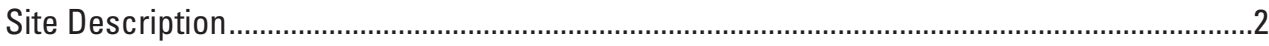

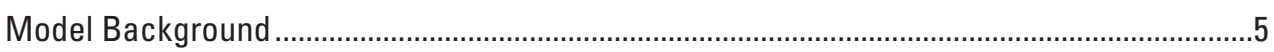

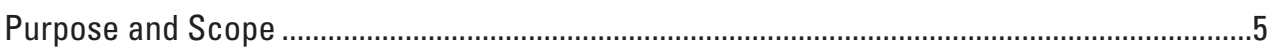

Methods

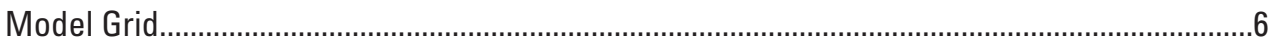

Model Data and Development.............................................................................................

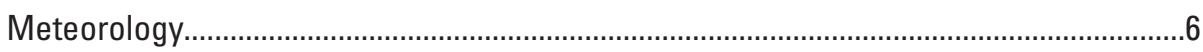

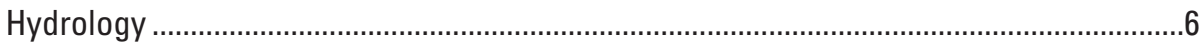

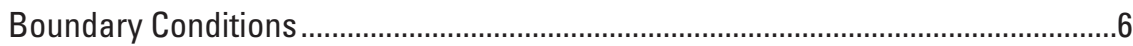

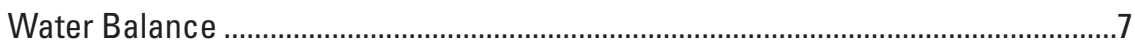

Water Temperature and Water Quality ...............................................................................

Boundary Condition Data .................................................................................

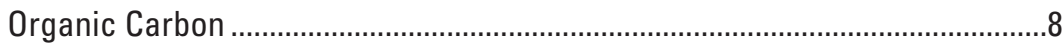

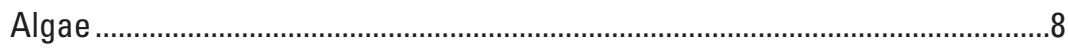

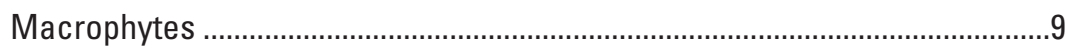

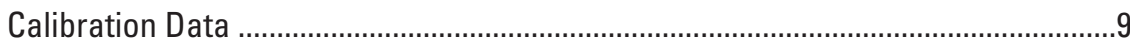

Model Rates and Parameter Coefficients ...........................................................

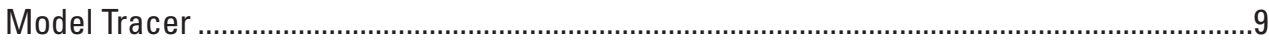

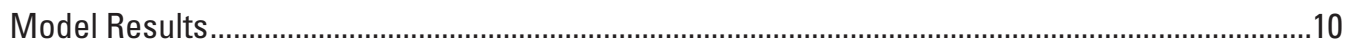

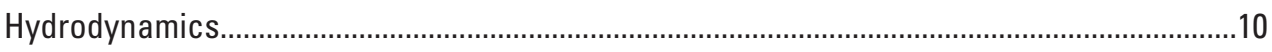

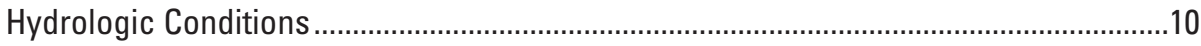

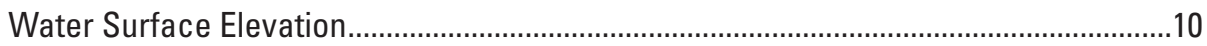

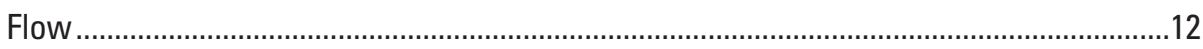

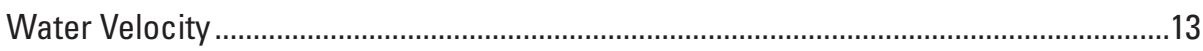

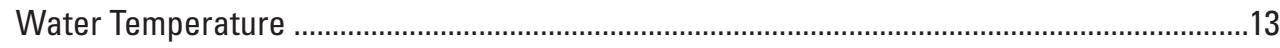

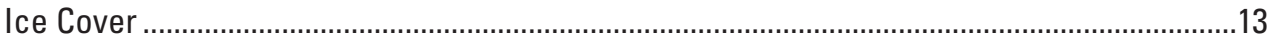

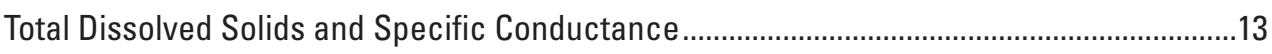

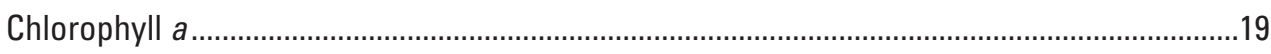

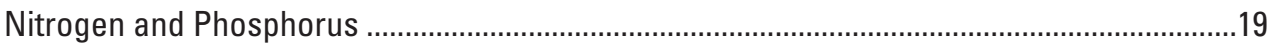

Particulate and Dissolved Organic Carbon .......................................................................2

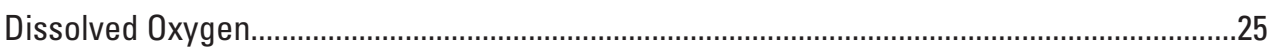

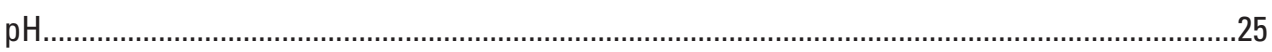

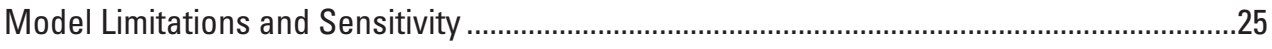

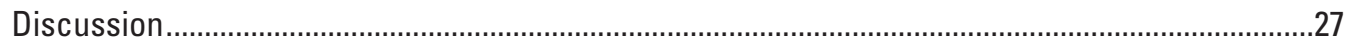

Klamath Straits Drain Mixing with Klamath River ............................................................2

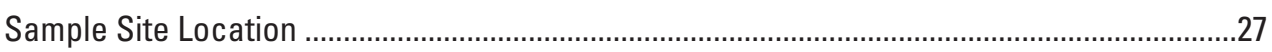

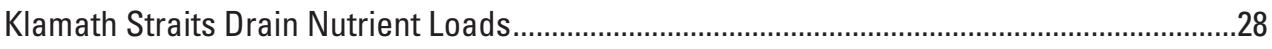

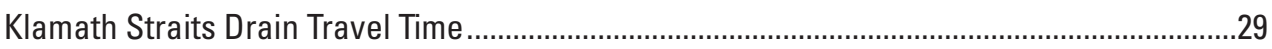

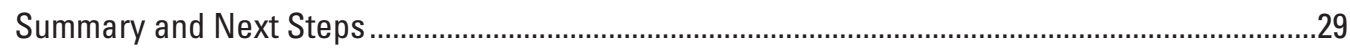

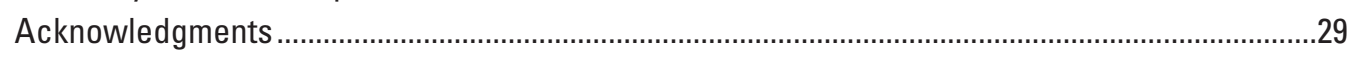

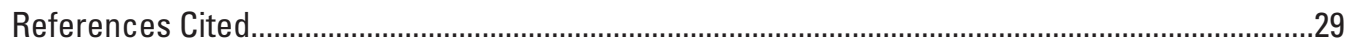




\section{Figures}

1. Maps showing study area, site locations $(A)$, and model segments and waterbody (WB) groupings $(B)$ in the Upper Klamath River and Lost River Basins, Oregon and California

2. Graph showing flow at three locations, Klamath Straits Drain, Upper Klamath River and Lost River Basins, Oregon and California, 2012-15...

3. Graphs showing daily water-surface elevation in Klamath Straits Drain, Upper Klamath River and Lost River Basins, Oregon and California, 2012-15.

4. Graphs showing measured and modeled flow at Klamath Straits Drain at Highway 97, downstream of the F-FF pumps, Oregon and California, calendar years 2012-15

5. Photograph and cross sections showing velocity direction at Klamath Straits Drain downstream of Highway 97, Oregon and California, 2012-15

6. Graphs showing modeled and measured velocity, Klamath Straits Drain at Highway 97, Oregon, calendar years 2012-15

7. Graphs showing measured and modeled water temperature, Klamath Straits Drain at Highway 97, Oregon, calendar years 2012-15.

8. Graph showing measured specific conductance at 1-meter depth at sites 420451121510000 Klamath Straits Drain at Highway 97 and 420853121505500 Klamath River at Miller Island, Oregon, 2012-15.

9. Graphs showing Klamath Straits Drain at Highway 97 modeled and measured specific conductance, modeled specific conductance upstream on the Klamath Straits Drain, and measured specific conductance downstream on the Klamath River $(A)$, and pump flow at the F-FF pumps (B), August-September 2014.

10. Graphs showing modeled and measured specific conductance, chlorophyll a, and nitrogen constituents, Klamath Straits Drain at Highway 97, Oregon, April-December 2012, January-December 2013, January-December 2014, and January-March 2015

11. Graphs showing measured and modeled phosphorus and carbon constituents, dissolved oxygen, and pH, Klamath Straits Drain at Highway 97, Oregon, April-December 2012, January-December 2013, January-December 2014, and January-March 2015 


\section{Figures-Continued}

12. Graphs showing components of total phosphorus $(A)$ and total nitrogen $(B)$ in Klamath Straits Drain at site Klamath Straits Drain Headworks, Oregon, 2012-15, as determined from measured data

13. Graphs showing components of total phosphorus $(A)$ and total nitrogen $(B)$ in Klamath Straits Drain at site Klamath Straits Drain at Highway 97, Klamath Straits Drain Headworks, Oregon and California, 2012-15, as determined from measured data

14. Graphs showing modeled spatial variation in dissolved inorganic nutrients (nitrate, ammonia, orthophosphorus) along Klamath Straits Drain, Oregon and California, on four selected dates in 2013.

15. Graphs showing average modeled internal kinetic fluxes for orthophosphorus (P04) components in waterbody 2, including model segments 15-30, and water body 3, including segments 31-36 of the Klamath Straits Drain model, Oregon, 2013

16. Graphs showing annual cycle of measured daily mean dissolved oxygen concentrations at Klamath Straits Drain near Highway 97 (site 420451121510000), Oregon, January 1, 1989-December 31, 2017

17. Graph showing modeled appearance of Klamath River tracer at locations in Klamath Straits Drain, Oregon and California, in 2012 (normal hydrologic year) and 2014 (a dry hydrologic year)

\section{Tables}

1. Sampling sites, Klamath Straits Drain, Oregon and California, 2012-15 ..........................6

2. Klamath Straits Drain model parameters that differed from the Klamath River model .10

3. Goodness-of-fit statistics for site KSD97, comparing measured data to model results at the same date and time 


\section{Conversion Factors}

U.S. customary units to International System of Units

\begin{tabular}{|c|c|c|}
\hline Multiply & By & To obtain \\
\hline \multicolumn{3}{|c|}{ Length } \\
\hline foot $(\mathrm{ft})$ & 0.3048 & meter $(\mathrm{m})$ \\
\hline mile (mi) & 1.609 & kilometer $(\mathrm{km})$ \\
\hline \multicolumn{3}{|c|}{ Volume } \\
\hline gallon (gal) & 3.785 & liter (L) \\
\hline gallon (gal) & 0.003785 & cubic meter $\left(\mathrm{m}^{3}\right)$ \\
\hline cubic foot $\left(\mathrm{ft}^{3}\right)$ & 0.02832 & cubic meter $\left(\mathrm{m}^{3}\right)$ \\
\hline \multicolumn{3}{|c|}{ Flow rate } \\
\hline foot per second $(\mathrm{ft} / \mathrm{s})$ & 0.3048 & meter per second $(\mathrm{m} / \mathrm{s})$ \\
\hline cubic foot per second $\left(\mathrm{ft}^{3} / \mathrm{s}\right)$ & 0.02832 & cubic meter per second $\left(\mathrm{m}^{3} / \mathrm{s}\right)$ \\
\hline \multicolumn{3}{|c|}{ Mass } \\
\hline ounce, avoirdupois (oz) & 28.35 & $\operatorname{gram}(\mathrm{g})$ \\
\hline pound, avoirdupois (lb) & 0.4536 & kilogram (kg) \\
\hline
\end{tabular}

International System of Units to U.S. customary units

\begin{tabular}{lll}
\hline \multicolumn{1}{c}{ Multiply } & By & \multicolumn{1}{c}{ To obtain } \\
\hline meter $(\mathrm{m})$ & Length & \\
kilometer $(\mathrm{km})$ & 3.281 & foot $(\mathrm{ft})$ \\
& 0.6214 & mile $(\mathrm{mi})$ \\
\hline liter $(\mathrm{L})$ & Volume & \\
cubic meter $\left(\mathrm{m}^{3}\right)$ & 0.2642 & gallon $(\mathrm{gal})$ \\
cubic meter $\left(\mathrm{m}^{3}\right)$ & 264.2 & gallon $(\mathrm{gal})$ \\
& 35.31 & cubic foot $\left(\mathrm{ft}^{3}\right)$ \\
\hline cubic meter per second $\left(\mathrm{m}^{3} / \mathrm{s}\right)$ & Flow rate & \\
\hline & 35.31 & cubic foot per second $\left(\mathrm{ft}^{3} / \mathrm{s}\right)$ \\
\hline gram $(\mathrm{g})$ & Mass & \\
kilogram $(\mathrm{kg})$ & 0.03527 & ounce, avoirdupois $(\mathrm{oz})$ \\
\hline
\end{tabular}

Temperature in degrees Celsius $\left({ }^{\circ} \mathrm{C}\right)$ may be converted to degrees Fahrenheit $\left({ }^{\circ} \mathrm{F}\right)$ as:

$$
{ }^{\circ} \mathrm{F}=\left(1.8 \times{ }^{\circ} \mathrm{C}\right)+32 .
$$

\section{Datums}

Vertical coordinate information is referenced to the National Geodetic Vertical Datum of 1929 (NGVD29), which is equivalent to Bureau of Reclamation datum in the study area.

Horizontal coordinate information is referenced to the North American Datum of 1927 (NAD 27).

Elevation, as used in this report, refers to distance above the vertical datum. 


\section{Supplemental Information}

Specific conductance is given in microsiemens per centimeter at 25 degrees Celsius $(\mu \mathrm{S} / \mathrm{cm}$ at $\left.25^{\circ} \mathrm{C}\right)$.

Concentrations of chemical constituents in water are given in either milligrams per liter ( $\mathrm{mg} / \mathrm{L})$ or micrograms per liter ( $\mu \mathrm{g} / \mathrm{L})$.

\section{Abbreviations}

$\begin{array}{ll}\text { DOC } & \text { dissolved organic carbon } \\ \text { DOM } & \text { dissolved organic matter } \\ \text { KSDH } & \text { Klamath Straits Drain Headworks } \\ \text { KSDT } & \text { Klamath Straits Drain at Township Road } \\ \text { KSD97 } & \text { Klamath Straits Drain at Highway } 97 \\ \text { NC } & \text { North Canal site } \\ \text { POC } & \text { particulate organic carbon } \\ \text { TDS } & \text { total dissolved solids } \\ \text { TMDL } & \text { total maximum daily load } \\ \text { USGS } & \text { U.S. Geological Survey }\end{array}$





\title{
Modeling Hydrodynamics, Water Temperature, and Water Quality in Klamath Straits Drain, Oregon and California, 2012-15
}

\author{
By Annett B. Sullivan and Stewart A. Rounds
}

\section{Executive Summary}

Located southwest of Klamath Falls, Oregon, Klamath Straits Drain is a 10.1-mile-long canal that conveys water uphill and northward through the use of pumps before discharging to the Klamath River. Klamath Straits Drain traverses an area that historically encompassed Lower Klamath Lake. Currently, the Drain receives water from farmland and from parts of the Lower Klamath Lake National Wildlife Refuge. To support water-quality improvement in Klamath Straits Drain, a hydrodynamic and water-temperature model was constructed and calibrated for calendar years 2012-15 with the two-dimensional model CE-QUAL-W2 (version 4.0). Water quality was calibrated for a subset of that time, from April 1, 2012 to March 31, 2015. Flows in calendar year 2012 were within the normal range, while calendar years 2013-15 were dry years. Significant findings from this study include:

- In the years studied, only limited flow entered Klamath Straits Drain at the upstream Headworks (KSDH) site. Most flow entered the Drain between KSDH and the E-EE pumps near Township Road through several irrigation channels and ditches. Few data were available to describe the quality of this water for the period of study.

- The E-EE and F-FF pumps along Klamath Straits Drain mainly operated automatically to keep water levels relatively steady. Ten-minute flow data at streamgage 11509340, downstream of the F-FF pumps, showed high-frequency on/off switching of the F-FF pumps. Combined with daily mean flow data from the F-FF pumps, the downstream 10-minute flow data allowed estimation of 10-minute pumping rates for the F-FF pumps. Paper pump charts showed the existence of short-term variability at the E-EE pumps; however, daily pump data were used at the E-EE pump location in the model.
- Water temperature in Klamath Straits Drain varied from less than 5 degrees Celsius $\left({ }^{\circ} \mathrm{C}\right.$ ) (with occasional ice cover in December-January) to greater than 20 ${ }^{\circ} \mathrm{C}$ in May-September. In the years studied, specific conductance was typically $250-850$ microsiemens per centimeter, higher than Klamath River specific conductance (typically 100-200 microsiemens per centimeter).

- Increased chlorophyll $a$ in autumn and winter, along with supersaturated oxygen concentrations, indicated algal blooms in the Drain at that time of year. The blooms were most likely diatoms, based on the timing of blooms sampled elsewhere.

- Total nitrogen concentration was as much as $5.5 \mathrm{mg} / \mathrm{L}$, with most in dissolved organic and particulate forms, and lower amounts in ammonia and nitrate+nitrite. Total phosphorus concentrations were distributed between orthophophorus (at a median concentration of $0.15 \mathrm{mg} / \mathrm{L}$ ) and organic and particulate forms (at a median concentration of $0.13 \mathrm{mg} / \mathrm{L}$ ). Most of the organic carbon in the Klamath Straits Drain was in dissolved rather than particulate form.

- Newly collected water-quality data for April 1 , 2012-March 31, 2015 helped provide the impetus for this modeling study. However, a lack of some data still hindered the construction and calibration of this model. The model would benefit from additional data to describe water-quality boundary conditions, water-quality calibration data upstream of the F-FF pumps, short-term E-EE pump operations, and channel bathymetry in the reach between Highway 97 and the confluence with the Klamath River.

- Klamath River water mixed upstream into the Klamath Straits Drain, up to the Klamath Straits Drain F-FF pumps at Highway 97, when the F-FF pumps were not operating for periods of hours to days. The F-FF pumps were off for many days during this study, especially during dry years. 
- The boundary between Klamath Straits Drain and the Klamath River was best modeled with an external head condition, which allows exchange of water between the river and the drain in both directions, upstream and downstream.

- Currently there is a flow gage, water-quality monitor, and a water-quality sampling site located downstream of the F-FF pumps, in the reach where Klamath Straits Drain water can mix with Klamath River water. To sample solely Klamath Straits Drain water, water samples would need to be collected only when the F-FF pumps are actively pumping. Alternately, the sampling location could be moved upstream of the pumps. Interpretation and use of historical waterquality data at the Klamath Straits Drain at Highway 97 site should be done in conjunction with information on pump activity to help inform whether mixing with Klamath River water may have occurred.

- Total 2014 (a dry year) phosphorus loads from the Drain to the Klamath River were lower and closer to total maximum daily load (TMDL) allocations, as compared to 2013, a year with greater flow and pumping.

- Modeled travel time through the Klamath Straits Drain, from Headworks to its confluence with the Klamath River, ranged from approximately 24 hours at high flow to 16 days or more, depending on how many days the pumps were turned off. The longer travel times are sufficient for important water-quality transformations, such as algal growth and organicmatter decomposition.

This newly constructed model of the Klamath Straits Drain simulates flow, water levels, water temperature, and water quality with acceptable accuracy but with certain data limitations. This model should prove useful in evaluating potential strategies for flow and water-quality management and restoration.

\section{Introduction}

The Klamath Straits Drain (fig. $1 A$ ) is a canal that flows into the Klamath River between Link River Dam and Keno Dam, approximately $10 \mathrm{mi}$ southwest of the town of Klamath Falls in south-central Oregon. Klamath Straits Drain is named as a nonpoint source in the Klamath River TMDL, which requires a more-than 85 percent reduction of total phosphorus, total nitrogen, and 5-day biochemical oxygen demand (BOD5) in waters discharged from the Klamath Straits Drain to the Klamath River (Oregon Department of Environmental Quality,
2017). Klamath Straits Drain also is named as a nonpoint source and impoundment in the Lost River TMDL, which provided dissolved inorganic nitrogen and carbonaceous biochemical oxygen demand (CBOD) load allocations and which required dissolved oxygen augmentation for Klamath Straits Drain (Oregon Department of Environmental Quality, 2017). In addition to these released TMDLs, Klamath Straits Drain also has a designation for arsenic and Escherichia coli (E.coli) on Oregon's list of impaired waterbodies (the "303[d] list") as "Category 5: Water quality limited, TMDL needed."

The availability of new flow and water-quality datasets collected in the Klamath Straits Drain area for 2012-15 prompted the initiation of this study in order to develop a hydrodynamic, water-temperature, and water-quality model of the Klamath Straits Drain. Such models provide information on the most important controlling processes and can be used as tools to assess the potential effects of management actions on water quality. As such, they can be useful tools for the planning of water-resource management and restoration efforts.

This study was one result of a partnership between the Bureau of Reclamation, U.S. Geological Survey, and Watercourse Engineering, Inc., to study and model parts of the Klamath River and Lost River. This group has collected field data (Sullivan and others, 2008, 2009), reported on water-quality processes (Poulson and Sullivan, 2010; Sullivan and others, 2010; Deas and Vaughn, 2011), constructed models of the Link-Keno reach of the Klamath River and Link River (Sullivan and others, 2011; Sullivan, Rounds, and others, 2013; Sullivan and Rounds, 2016), and reported model results to evaluate different scenarios and management strategies (Sullivan and others, 2012; Sullivan, Sogutlugil, and others, 2013).

\section{Site Description}

Klamath Straits Drain is an unlined earthen channel, approximately 10.1 miles long, that transfers water north and west into the Klamath River (fig. 1B). Klamath Straits Drain was originally constructed in the 1940s with Pump Plant E near Township Road and Pump Plant F near Highway 97. The $\mathrm{E}$ and $\mathrm{F}$ locations both contain three pumps to help convey water. Klamath Straits Drain was enlarged in the 1970 s to increase its flow capacity from 300 to $600 \mathrm{ft}^{3} / \mathrm{s}$ ( 8.5 to 17 $\mathrm{m}^{3} / \mathrm{s}$ ). The new pumps, named EE and FF and co-located with pumps $\mathrm{E}$ and $\mathrm{F}$, brought the total number of pumps at each site to six. During 2012-15, daily Klamath Straits Drain pump flows at the F-FF pumps ranged from 0 to $374 \mathrm{ft}^{3} / \mathrm{s}$ ( 0 to 10.6 $\left.\mathrm{m}^{3} / \mathrm{s}\right)$. These flows represented an average of 6 percent of the measured daily streamflow at the Klamath River at Keno streamgage downstream (site 11509500), with a range of 0-66 percent. 


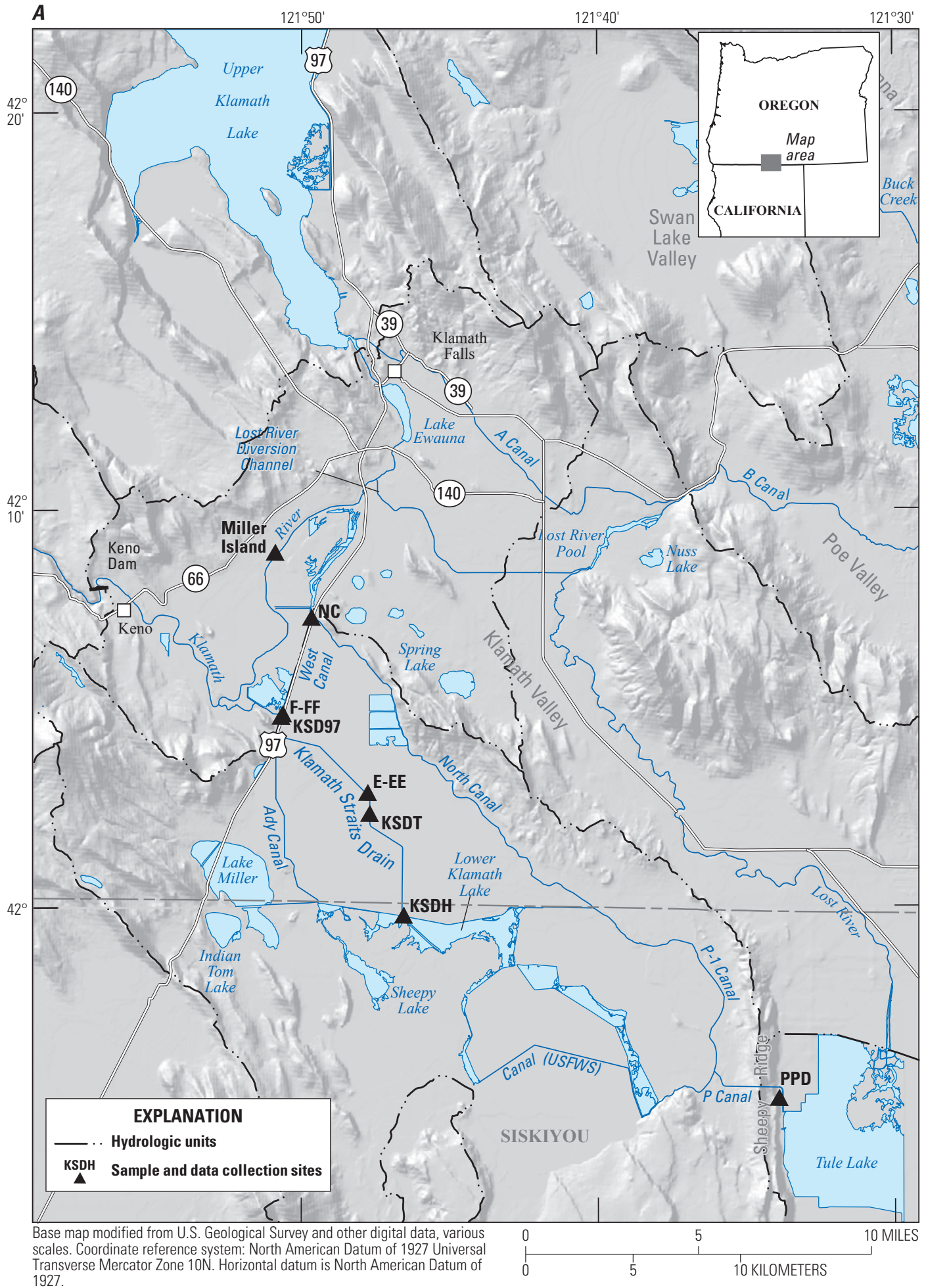

Figure 1. Study area, site locations $(A)$, and model segments and waterbody (WB) groupings $(B)$ in the Upper Klamath River and Lost River Basins, Oregon and California. See table 1 for detailed information on abbreviated sample and data-collection sites. 


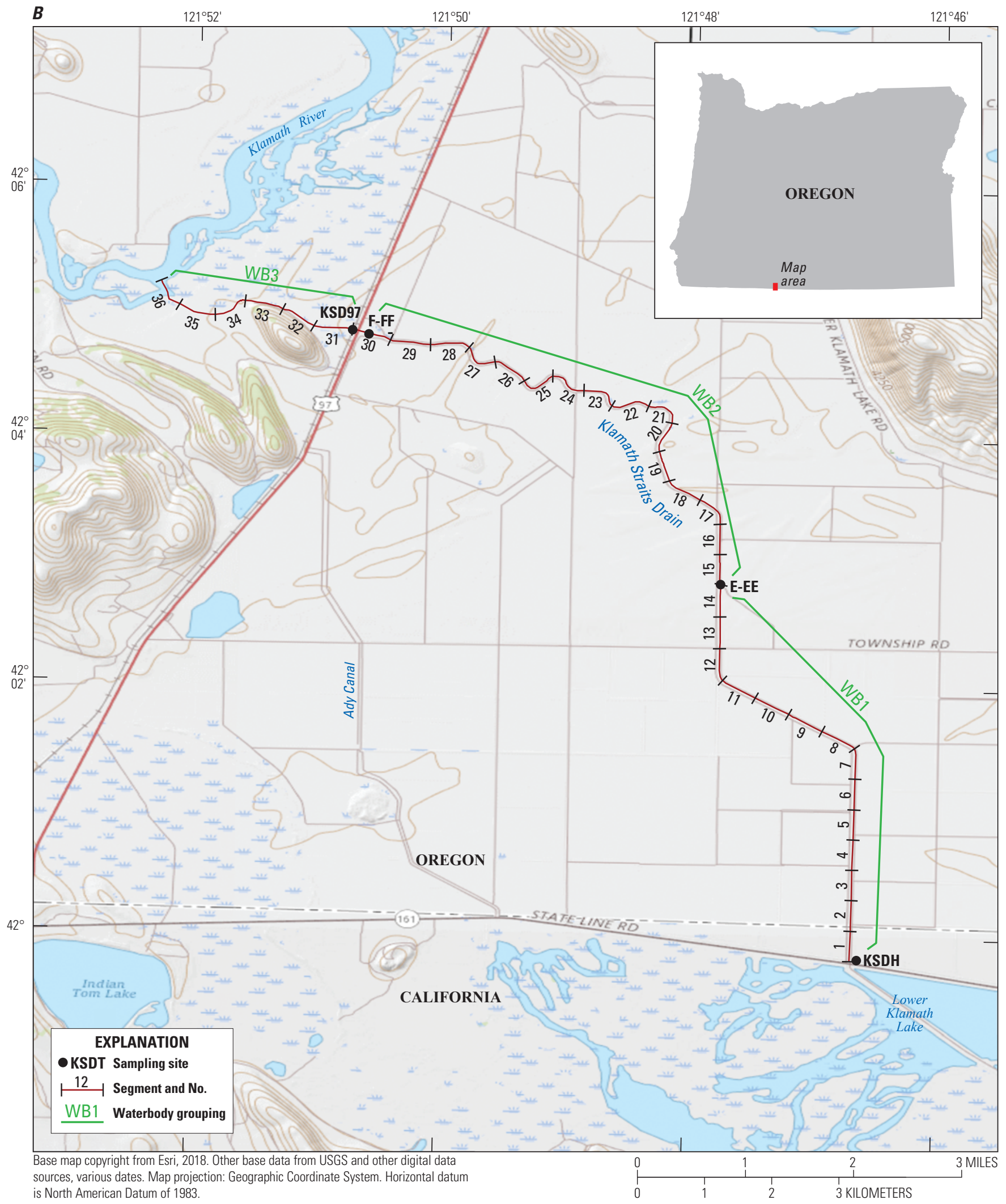

Figure 1.-Continued 
The area surrounding the Klamath Straits Drain was historically part of Lower Klamath Lake, which was drained as part of the Bureau of Reclamation Klamath Project that converted land to irrigated agriculture. Soils in the Klamath Straits Drain area are classified as Teeters silt loam and Tulana silt and silt loam - poorly drained flood plain and lacustrine deposits (Cahoon, 1985). These soils are suitable for crops such as barley, wheat, alfalfa and other hay, potatoes, and irrigated pasture (Klamath Drainage District, 2015). Grasses and annual forbs are common on Klamath Straits Drain channel banks. Few trees or shrubs are found in this area.

The Klamath Straits Drain area is also an important stopover for millions of ducks and geese that follow the Pacific Flyway through the Upper Klamath Basin. National Wildlife Refuges at Tule Lake, to the southeast of Klamath Straits Drain, and at Lower Klamath Lake, south of Klamath Straits Drain's Headworks (KSDH), support these migrating wildfowl.

The climate of the Klamath Straits Drain area is typified by dry warm summers and wet cool winters. Average annual precipitation at Klamath Falls is 13.5 inches, with two-thirds of that falling as snow between October and March (Oregon Department of Environmental Quality, 2017).

The Headworks (KSDH) receive water from the Lower Klamath Lake National Wildlife Refuge (Mayer, 2005) and farther upstream from Tule Lake via Pump Plant D. Water also enters Klamath Straits Drain from irrigation and drainage canals along its entire length. In the years of this study, much of the irrigation water that was eventually returned to the Drain was sourced from the Klamath River by withdrawals through Ady and North Canals.

Most of the Klamath Straits Drain and surrounding area is lower in elevation than the Klamath River, so the E-EE and F-FF pump stations are sited along the Drain to move water uphill and towards the Klamath River. These two pump stations, operated by the Bureau of Reclamation, lift water approximately 10 feet (ft) in elevation at each location.

\section{Model Background}

The Klamath Straits Drain model was developed with CE-QUAL-W2 version 4.0, a two-dimensional (longitudinal, vertical) water-quality, temperature, and flow model (Cole and Wells, 2016). The model comprises the entire Klamath Straits Drain, from the Headworks (KSDH) to the confluence with the Klamath River's Link-Keno reach.

Originally, the Klamath Straits Drain was included as a tributary in the CE-QUAL-W2 model for the Link-Keno reach of the Klamath River developed by Sullivan and others (2011) and Sullivan, Rounds, and others (2013), with flow, temperature, and water quality inputs for the Drain based on measured data collected at KSD97 for 2006-09 and 2011. However, the entire reach of the Klamath Straits Drain channel was not included in that previously developed Klamath River model. In this study, the entire reach of the Klamath Strait Drain downstream of KSDH was modeled. The Klamath River and Klamath Straits Drain models may be connected in the future, but not at the time of this writing, as these models were developed for different time periods. For future work, the Link-Keno model will be set up and calibrated to coincide with the Klamath Straits Drain model's calibration in order to link the models.

Klamath Straits Drain was included in a CE-QUAL-W2 model of the Lost River that was built to assist with Lost River TMDL development (Tetra Tech, Inc., 2005; Rounds and Sullivan, 2013). That model simulated January-December 1999 and January-August 2004 and was used to inform some aspects of development of this study's Klamath Straits Drain model. However, a new model grid, model input files, and model parameters were used in this new model of the Klamath Straits Drain, due to the availability of expanded and updated information.

\section{Purpose and Scope}

The purpose of this study was to build and calibrate a hydrodynamic, water-temperature, and water-quality model of the Klamath Straits Drain. This work was completed to fully use recent flow, temperature, and water-quality data, and to use the newly collected data to build a model. The new model could better inform and evaluate potential management and restoration strategies. Flow and velocity data at 10-minute intervals were available from a new streamgage at Highway 97 (Klamath Straits Drain near Worden, Oregon; site 11509340; KSD97). Water-quality data were collected at several sites during 2012-15 as part of a larger study on water-quality loads in the Lost River basin (Schenk and others, 2018).

The Klamath Straits Drain model was developed for its entire 10.1-mile length, from KSDH to its confluence with the Klamath River. The model was developed and calibrated for hydrodynamics and water temperature for separate, full calendar years $2012-15$. The model was calibrated for water quality for a subset of that time, for April 1, 2012, through March 31, 2015, due to limited data availability. Modeled constituents included flow, velocity, water level, water temperature, nitrogen and phosphorus species, organic matter, dissolved oxygen, $\mathrm{pH}$, and algae. 


\section{Methods}

The model was developed in several steps. First, a model grid was constructed to convey water. Then, model input files were created to represent meteorological conditions, flow, water temperature, and water quality for inflows. A water balance was completed to quantify and account for ungaged inputs and ensure proper simulation of water levels. Finally, temperature and water quality were calibrated by comparing model predictions to measured data at calibration locations.

\section{Model Grid}

The model grid consisted of 36 segments (longitudinal model units) ranging in length from 434 to 476 meters $(1,424-1,562 \mathrm{ft})$. The total length of the Klamath Strait Drain model grid is $16.2 \mathrm{~km}$ (10.1 miles) from Klamath Straits Drain Headworks (KSDH) to its confluence with the Klamath River.

The segments were grouped into three CE-QUAL-W2 waterbodies, where a waterbody is a group of segments. The purpose of separate waterbodies was to allow the model to simulate the elevation lift at the pump locations at waterbody boundaries. Waterbody 1 included segments from KSDH to the E-EE pumps; Waterbody 2 included segments form the E-EE pumps to the F-FF pumps; and Waterbody 3 included segments from the F-FF pumps to the confluence with the Klamath River (fig. 1B).

Model layer height was a uniform $2 \mathrm{ft}$. Layer width decreased from top to bottom in each segment to approximate the channel shape. To assist in defining layer widths, channel shape information was obtained from plans in the Environmental Statement (Bureau of Reclamation, 1974) and from U.S. Geological Survey (USGS) acoustic Doppler crosssectional measurements at sites KSD97 and KSDT (table 1).

\section{Model Data and Development}

\section{Meteorology}

To build the CE-QUAL-W2 meteorological input file, air temperature, dew point temperature, wind speed, wind direction, and cloud-cover data were obtained from the Klamath Falls airport station (National Ocean and Atmospheric Administration, 2018). Measurements were made approximately every hour. Hourly measurements of solar radiation were obtained from the Lower Klamath Lake meteorological station operated by U.S. Fish and Wildlife Service. Daily precipitation was obtained from the Klamath Falls Agrimet station KFLO (U.S. Bureau of Reclamation, 2016). The temperature of precipitation was set equal to the daily mean air temperature from KFLO, with air temperatures below 0 degrees Celsius set to 0 .

\section{Hydrology}

\section{Boundary Conditions}

The upstream inflow to the model was at KSDH (table 1, fig. 1A). Water transfers at pump locations were implemented in the model with dynamic pump input files at the E-EE and F-FF pump locations. The E-EE pump flows were set as daily pump flows recorded by Reclamation.

At the F-FF pumps, two sources of flow data were available: daily pump flows from Reclamation and 10-minute flow data from USGS streamgage 11509340, immediately downstream of the F-FF pumps. The 10-minute flow data captured the pump behavior but also measured other flow effects. For instance, the Reclamation pumps were inactive for

Table 1. Sampling sites, Klamath Straits Drain, Oregon and California, 2012-15

[Site locations shown in figure 1. Type: Q, flow; T, temperature; WQ, water quality. Use: C, model calibration; I, model input; Q, flow; U, velocity; WSEL, water surface elevation. Abbreviations: ID, identification; NA, not applicable; Reclamation, Bureau of Reclamation; USGS, U.S. Geological Survey]

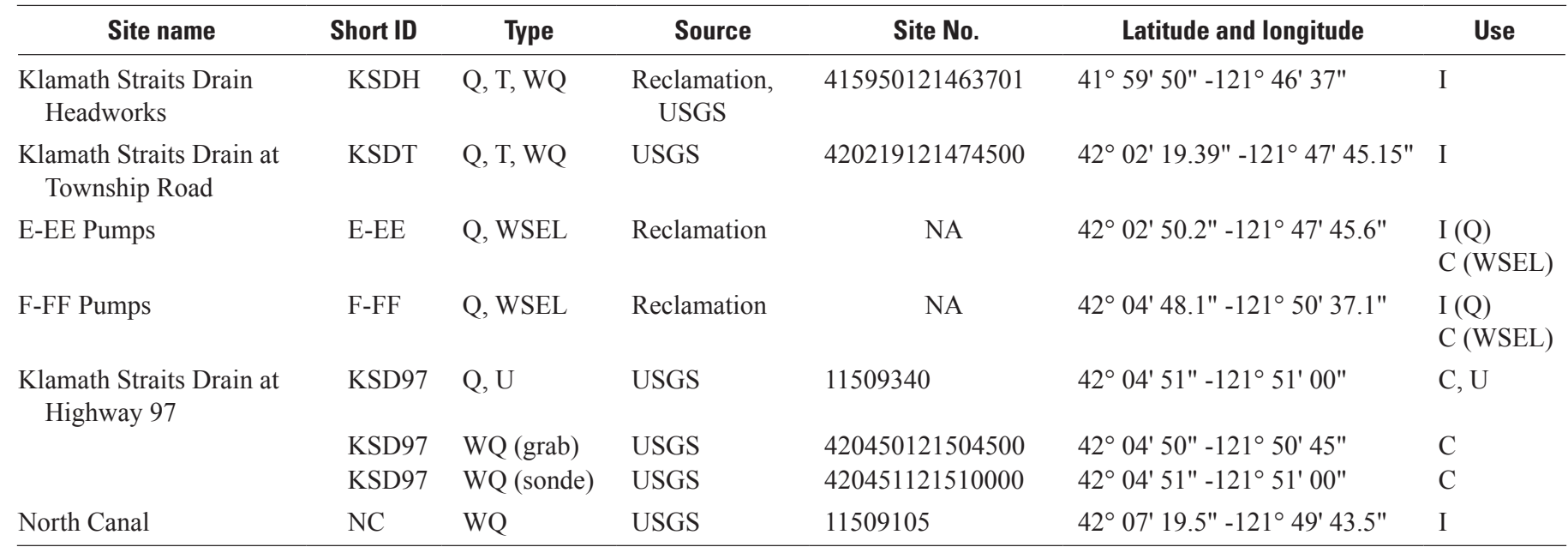


January 22, 2015-March 31, 2015, with no pump flows in the daily dataset. However, the streamgage at 11509340 measured both positive and negative flow for this period; this flow is likely caused by wind and water density differences or water surface elevation variations in the Klamath River downstream of the F-FF pumps.

A blended approach was taken to formulate the F-FF pump input files. The 10-minute streamgage data were observed to have a step function corresponding to the number of pumps in operation, so flow data first were averaged in ranges surrounding those steps. Flows less than $80 \mathrm{ft}^{3} / \mathrm{s}(2.3$ $\mathrm{m}^{3} / \mathrm{s}$ ) were set to zero pumping. The lowest pump capacity was $100 \mathrm{ft}^{3} / \mathrm{s}\left(2.8 \mathrm{~m}^{3} / \mathrm{s}\right)$. The resulting 10 -minute time series was averaged for the period of a day and compared to the daily average pump flows reported by Reclamation. The 10-minute time series was then corrected so that daily averages would match the Reclamation F-FF daily pump values more closely.

The downstream boundary of the Klamath Straits Drain model, at its confluence with the Klamath River, was constructed with a downstream head boundary. This boundary allowed water to move upstream or downstream, in and out of the model. The head boundary was set equal to measured Klamath River water surface elevations, corrected to be consistent with the Lower Klamath Lake datum used in the Klamath Straits Drain model. To implement the correction, 1.6 $\mathrm{ft}$ was subtracted from each Keno water surface elevation.

\section{Water Balance}

CE-QUAL-W2 uses a distributed tributary input that helps to close the water balance by distributing flow to all model segments in a reach weighted by segment surface area. These distributed tributary inputs represent flow errors in gaged flow inputs as well as all ungaged flows, including small channels, and groundwater flow or seepage. Distributed tributary inputs were initially determined for waterbodies 1 and 2 using the difference between the imposed Headworks (KSDH) and E-EE flows and the difference between the E-EE and F-FF flows, respectively. These pump flows were measured daily by Reclamation. Minor adjustments to distributed tributary flows were made during flow calibration, so that modeled and measured water surface elevations matched more closely. Water surface elevation information was available on a daily basis from Reclamation at the Klamath Straits Drain Headworks site and at the E-EE and F-FF pumps. For the latter, water-surface elevation data were available both at the sumps, located immediately upstream of the pumps, and at the discharges, located downstream of the pumps.

\section{Water Temperature and Water Quality}

\section{Boundary Condition Data}

Discrete water-quality sampling and analysis was done as described by Schenk and others (2018); results from that study comprised most of the water-quality data used to drive the Klamath Straits Drain model. The locations of key sampling and data-collecting stations are shown in figure $1 A$ and table 1.

As a brief synopsis of the water-quality methods, unfiltered water samples were collected for total nitrogen and total phosphorus. Samples were filtered with a $0.45 \mu \mathrm{m}$ filter for analysis of ammonia+ammonium (referred to as ammonia in this report), nitrate+nitrite, and orthophosphorus, and filtered with a glass fiber filter (about $0.7 \mu \mathrm{m}$ pore size) for dissolved organic carbon (DOC). The material retained on the glass fiber filter was analyzed for particulate carbon and nitrogen. Samples for analysis of chlorophyll $a$ also were collected on glass fiber filters.

At the Klamath Straits Drain Headworks (KSDH) site, samples were collected only when water was flowing (fig. 2). Measured dissolved oxygen, $\mathrm{pH}$, filtered orthophosphorus, ammonia, and nitrate+nitrite were used directly in the water-quality input file. Measured specific conductance was converted to estimated total dissolved solids, and inorganic suspended sediment was estimated from measured turbidity as described by Sullivan and others (2011).

When Klamath Straits Drain Headworks (KSDH) was not flowing, most of the water making up Klamath Straits Drain flow typically entered the Drain between KSDH and the E-EE pumps (fig. $1 \mathrm{~A}$ ). The quality of water in this reach was not measured in 2012-15. In 2016-17, water-quality samples for nutrients, particulate carbon, DOC, and chlorophyll $a$ were collected and analyzed monthly at the Klamath Straits Drain at Township Road site (KSDT, just upstream of the E-EE pumps, fig. $1 A$ ), with close-in-time samples at the Klamath Straits Drain at Highway 97 site. The relation of water quality at these two sites was analyzed via regression, excluding dates when the F-FF pumps were non-flowing. The regression relation was used with measured data at site KSD97 in 2012-15 to estimate water quality at the upstream parts of Klamath Straits Drain. A regression approach, however, has limitations. For example, it assumes that processes occurring in 2016-17 were valid for 2012-15. Also, sampling of the two sites in 2016-17 were separated in time by several hours, up to a day, so it assumes that that daily variability was minor. For parts of 1999-2000, water-quality monitors made hourly measurements at both KSDT and KSD97, allowing regressions between the two sites for water temperature, specific conductance, $\mathrm{pH}$, and dissolved oxygen. Dates were excluded from the regression when the F-FF pumps were not flowing. 


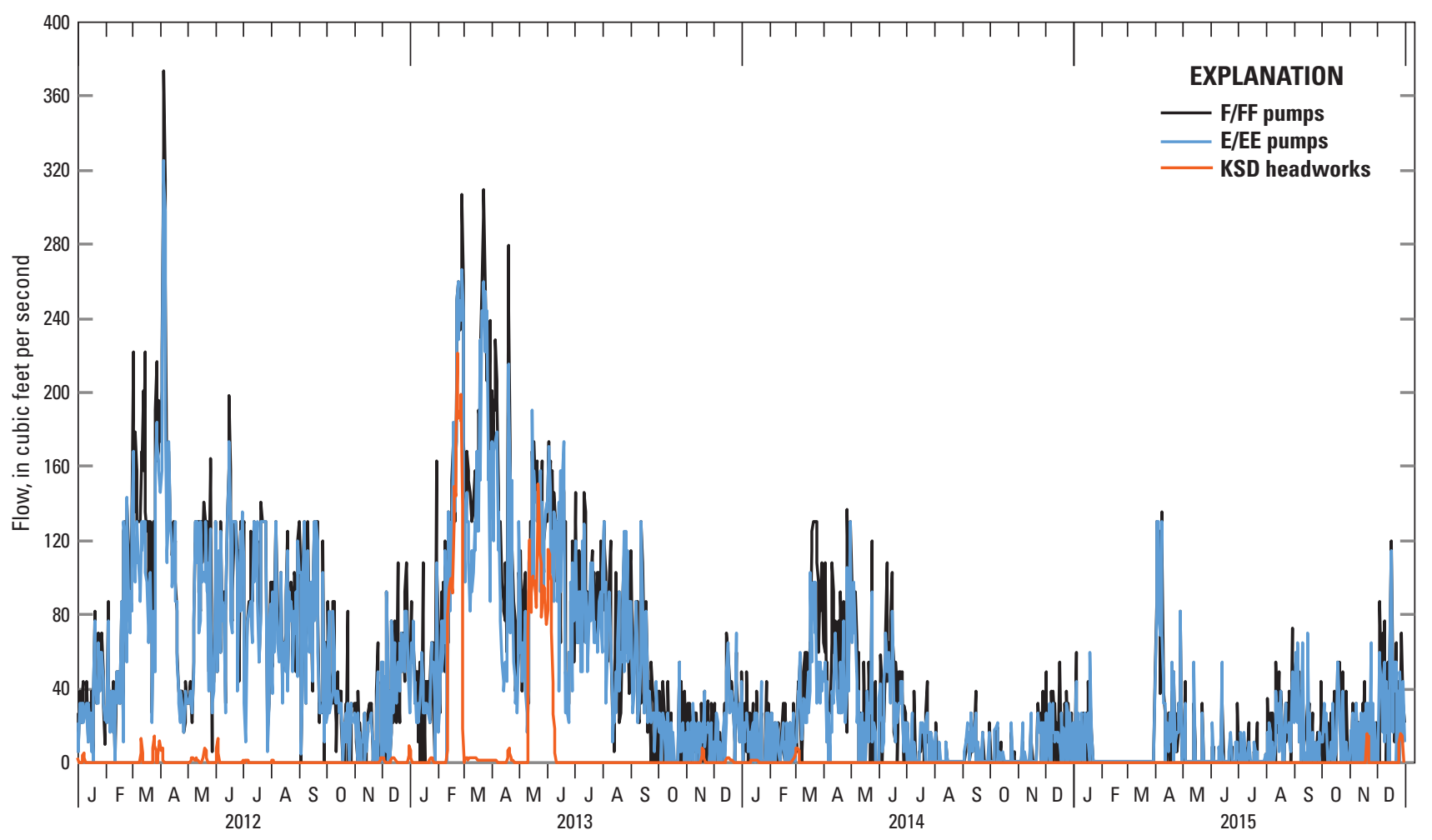

Figure 2. Flow at three locations, Klamath Straits Drain, Upper Klamath River and Lost River Basins, Oregon and California, 2012-15. See figure 1 for locations of these sites.

Water quality at the downstream model boundary (Klamath River at the mouth of Klamath Straits Drain) was estimated using grab-sample data collected from the North Canal, which draws water from the Klamath River approximately 3.5 miles upstream of the Klamath Straits Drain confluence.

\section{Organic Carbon}

For model input files, measured DOC was transformed into dissolved organic matter (DOM) as used in CE-QUAL-W2 with a stoichiometric ratio of 0.46 between carbon and organic matter. The DOM concentration was further separated into labile (quickly decomposing) and refractory (slowly decomposing) compartments. The separation was done in a consistent manner for Klamath Straits Drain organic matter, relative to the description of organic matter in the Link-Keno model (Sullivan and others, 2011; Sullivan, Rounds, and others, 2013) in summer and autumn, 5 percent of DOM was assumed to be labile; in winter and spring, 1 percent was assumed.

Measured particulate organic carbon (POC) was transformed into particulate organic matter for the model with the same stoichiometric ratio between carbon and organic matter of 0.46 . The particulate organic matter was then divided between labile and refractory components in a similar manner to what was done for the DOM.
Algae

No algal species data were available for calendar years 2012-15, though other algal species data were available for earlier years. In 2008, algal species were identified in water samples from the Klamath Straits Drain near Highway 97 from April through October, at approximately 2-week intervals (Sullivan and others, 2009). In that year, diatoms were dominant in spring, especially Nitzschia acicularis and Stephanodiscus hantaschii and Fragilaria construens. In June and early July, the blue-green algae Aphanizomenon flos-aquae was dominant. Algal biovolume was less than $1,000,000$ cubic micrometers per milliliter $\left(\mu \mathrm{m}^{3} / \mathrm{mL}\right)$ from mid-July through September, with a mix of diatoms, bluegreens, greens, cryphytophes, and dinoflagellates. Algal biovolume increased in October, with diatoms being dominant. A July 2004 sampling at KSDT found the cryptophytes Rhodomonas minuta and Cryptomonas erosa to be the dominant phytoplankton taxa.

Total algal concentrations were estimated for the Klamath Straits model inflows at KSDH, the distributed tributary between KSDH and E-EE pumps, and the distributed tributary between E-EE and F-FF pumps. The estimation was completed by using the chlorophyll $a$ concentration in micrograms per liter and multiplying by the model's ratio between algal biomass and chlorophyll $a$. 
In Klamath River Link-Keno model development, three algal groups were used: diatoms, blue-green algae, and a third community including green algae, cryptophytes, and other miscellaneous algal species. Without Klamath Straits Drain algal species data for each year, algal species distribution (to make up the total described above) for inflows was assumed to be 95 percent diatoms and 5 percent "other" from midNovember through early June, with 60 percent blue-green algae, 30 percent other algae, and 10 percent diatoms from mid-June through early-November. This rough allocation is mirrored in the available algal species data described above.

\section{Macrophytes}

As part of a larger effort to sample and document aquatic plants (macrophytes) in the Lost River, Eilers (2005) examined the macrophytes at KSDT in July 2004. Macrophyte coverage was measured as only 1 percent in a section across the channel. Eilers (2005) also stated that this site had steep banks and that most of the channel bottom was light-limited, given a measured 98.7 percent light reduction at 0.9 meter depth. The dominant macrophyte was coontail (Ceratophyllum demersum). Most of the plants were drifting, not attached to the bottom.

In contrast to the low macrophyte density reported in July 2004, Reclamation staff have noted locally thick macrophyte growths in parts of the Klamath Straits Drain during the model period 2012-15 (Shane Spiker, Bureau of Reclamation, oral commun., 2017). Density was estimated to be at maximum in July-August. A die-off was observed in August-September when macrophyte stems were broken off and flushed downstream. When present, macrophytes might trap sediment and could help build sand bars downstream of canal inflows. The presence of macrophytes was typically observed to begin in the area near the E-EE pumps, moving to the F-FF pump area later. Higher flow conditions kept macrophytes growth down.

Macrophytes were included in initial testing versions of the model, but not the final calibrated models. Macrophyte species delineation and quantification was not completed during the data collection in 2012-15, and there is no macrophyte data with which to calibrate the model for these years.

\section{Calibration Data}

Measured water-quality data at site KSD97 was compared to model output at that same location on the same date and time to check model performance. Data at KSD97 were collected from a continuous monitor that measured water temperature, specific conductance, dissolved oxygen, and $\mathrm{pH}$ hourly, and discrete water samples also were collected at this site for analysis of nutrients, carbon, and chlorophyll $a$ (Schenk and others, 2018).

\section{Model Rates and Parameter Coefficients}

Many model parameters were identical to those used in the previously developed Link-Keno model (Sullivan and others, 2011; Sullivan, Rounds, and others, 2013) though some parameters were modified. Model parameters that differed between models are shown in table 2.

\section{Model Tracer}

With the calibrated model, a conservative tracer was added only to the Klamath River external head boundary input file, located at the mouth of Klamath Straits Drain. The tracer was set to $10,000 \mathrm{mg} / \mathrm{L}$, constant through the entire year. In this run, no conservative tracer was added to any Klamath Straits Drain input files. Thus, any tracer that appeared in the Klamath Straits Drain would be sourced from the Klamath River. This tracer test was run for a normal hydrologic year (2012) and a dry hydrologic year (2014). Klamath Straits Drain output between KSD97 and the confluence with the Klamath River was examined for the appearance of this tracer.

In another model run, a conservative tracer was injected into the calibrated model at KSDH location, at both high and low flow, to evaluate travel time through the Klamath Straits Drain system. This tracer was transported through the entire modeled reach of the Klamath Straits Drain from KSDH to mouth. The time difference between the injection time and the time that the tracer peak reached the last model segment at Klamath Straits Drain mouth was considered to be the travel time through Klamath Straits Drain. 
Table 2. Klamath Straits Drain model parameters that differed from the Klamath River model.

[Klamath River model parameters taken from Sullivan and others (2011) and Sullivan, Rounds, and others (2013). Value: KRiver model, Klamath River model; KSD model, Klamath Straits Drain model. Abbreviations: ${ }^{\circ} \mathrm{C}$, degrees Celsius; m/d, meter per day; W/ $\mathrm{m}^{2}$, watt per square meter; SOD, sediment oxygen demand]

\begin{tabular}{|c|c|c|c|}
\hline \multirow{2}{*}{ Parameter } & \multicolumn{2}{|c|}{ Value } & \multirow{2}{*}{ Description } \\
\hline & KRiver model & KSD model & \\
\hline AR-Diatoms & 0.04 & 0.02 & Maximum respiration rate, $1 /$ day \\
\hline AM-Diatoms & 0.005 & 0.01 & Maximum algal mortality rate, $1 /$ day \\
\hline AS-Diatoms & 0.01 & 0.03 & Settling rate, $\mathrm{m} / \mathrm{d}$ \\
\hline ASAT-Diatoms & 45 & 15 & Light saturation intensity at max photosynthetic rate, $\mathrm{W} / \mathrm{m}^{2}$ \\
\hline AG-Other algae & 1.4 & 0.4 & Maximum algal growth rate, $1 /$ day \\
\hline AR-Other algae & 0.03 & 0.02 & Maximum respiration rate, $1 /$ day \\
\hline AM-Other algae & 0.005 & 0.01 & Maximum algal mortality rate, $1 /$ day \\
\hline AS-Other algae & 0.005 & 0.01 & Settling rate, $\mathrm{m} / \mathrm{d}$ \\
\hline AT1,2,3,4-Diatoms & $4,10,16,20$ & $2,4,5,9$ & Temperature parameters for rate function, ${ }^{\circ} \mathrm{C}$ \\
\hline AT1,2,3,4-Other algae & $12,22,25,35$ & $8,15,17,30$ & Temperature parameters for rate function, ${ }^{\circ} \mathrm{C}$ \\
\hline SEDK & 0.09 & 0.10 & First-order sediment decay rate, day $^{-1}$ \\
\hline FSOD & 0.101 & 0.80 & Fraction of the zero-order SOD rate used \\
\hline SEDBR & 0.002 & 0.01 & First-order sediment burial rate, day ${ }^{-1}$ \\
\hline SODT1,2 & 2,25 & 4,25 & Temperature parameters for SOD, ${ }^{\circ} \mathrm{C}$ \\
\hline SODK1,2 & $0.15,0.90$ & $0.01,0.99$ & Fraction of SOD at temperature parameters \\
\hline
\end{tabular}

\section{Model Results}

For the Klamath Straits Drain model, model output was compared to measured data, for the same date and time, at site KSD97. Error statistics calculated for these comparisons include mean error, mean absolute error, and root mean square error. The general magnitude and seasonal patterns between modeled output and measured data should correspond; however, an exact match is not expected, because measurements are made at a point, and model output at KSD97 represents averaged conditions in model cells that are 1,424-ft (433.9-m) long and 2-ft (0.61-m) high. Models are simplifications of nature, but a generally good fit between model output and measured data provides confidence that major processes are included and that the model can provide insight into management options.

\section{Hydrodynamics}

\section{Hydrologic Conditions}

Calendar year 2012 was a normal flow year, with 187 days greater than the median flow for each day of the year, using median measured flows in the Klamath River downstream of Keno Dam for 1996-2015. Calendar years 2013, 2014, and 2015 were low-flow years, with only 16, 60, and 54 days, respectively, having flow greater than the median for each day of the year. In years with low flow, less water was present to pump out of the area surrounding the Klamath
Straits Drain. At the F-FF pumps, there were 27 days with no pumping in 2012, 47 days in 2013, 161 days in 2014, and 210 days in 2015.

During this study (2012-15), little flow entered at KSDH most of the time (fig. 2). Instead, most flow entered the Klamath Straits Drain between the KSDH and the E-EE pumps through a network of drainage canals. Some additional flow entered the Drain between the E-EE and F-FF pumps.

\section{Water Surface Elevation}

Klamath Straits Drain water-surface elevation was lowest in its most upstream section between KSDH and the E-EE pumps, increased about 8-10 ft in the section downstream of the E-EE pumps, and increased about another $10 \mathrm{ft}$ downstream of the F-FF pumps. For the reaches between pumps, the Klamath Straits Drain water-surface elevation was relatively flat. The model was able to simulate the water surface elevations with generally good agreement between modeled and measured values (fig. 3). The model had more water-surface elevation variability than the measured data. This could be due, in part, to the difference in data frequency between the model E-EE and F-FF pump flow input files. The F-FF pump input file was developed with inputs at 10-minute intervals, while the E-EE pump input file was created with a daily timestep. Paper pump charts showed that the E-EE pump rates did vary on a sub-daily basis, but those data were not digitized, and thus that variability was not captured in the model inputs. 
2012

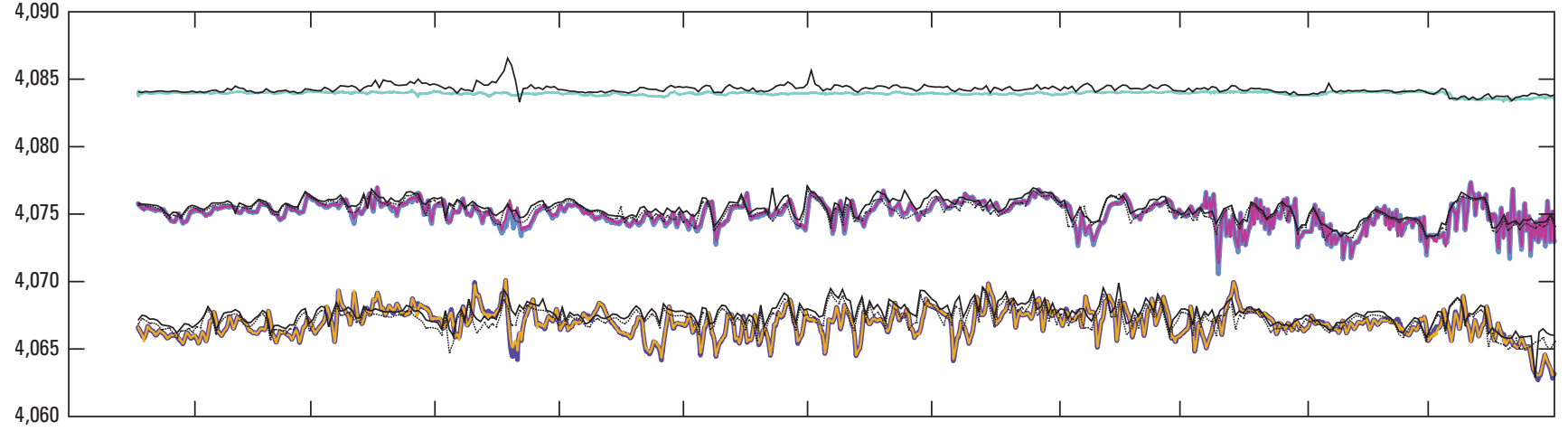

2013

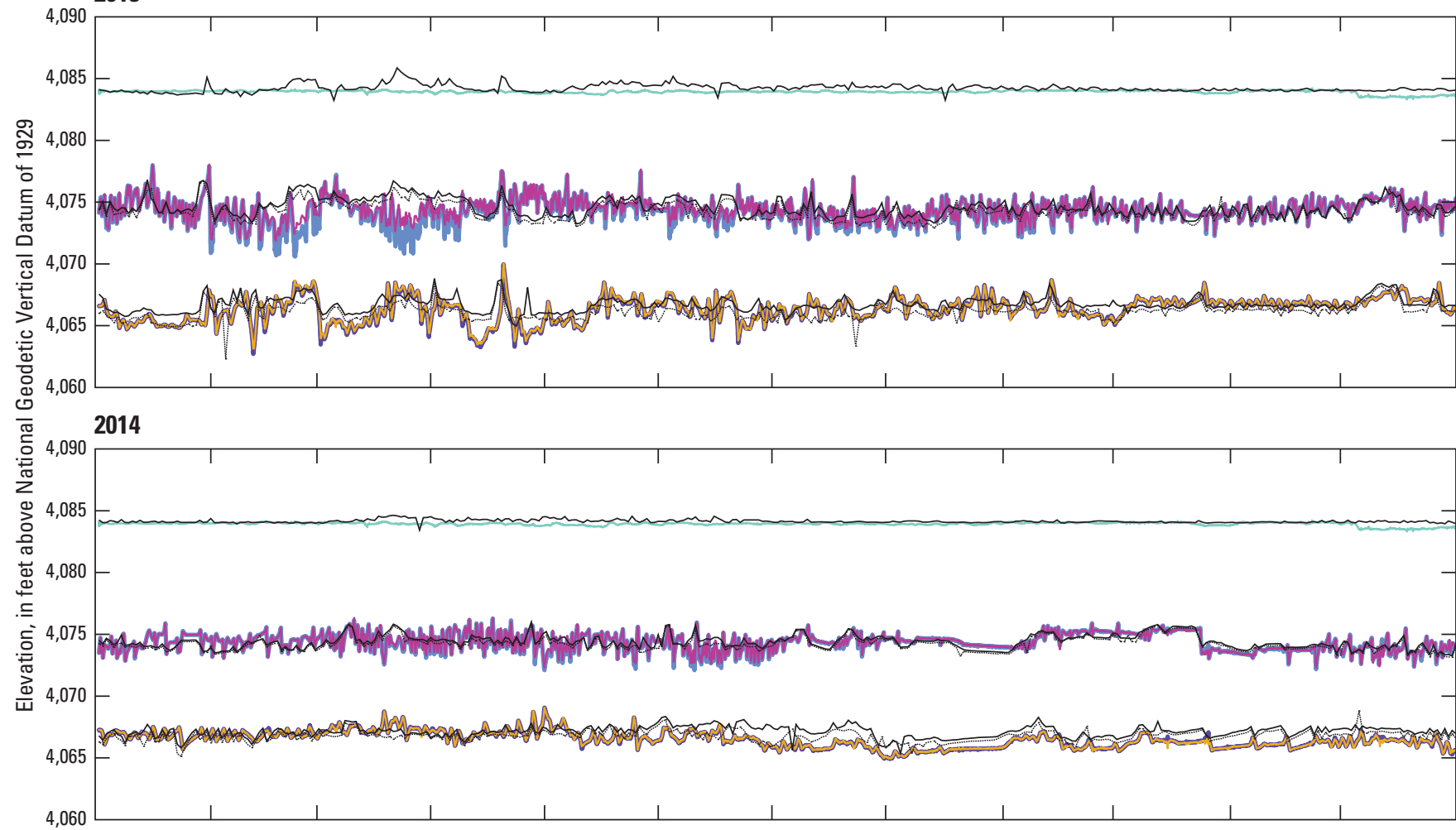

2015

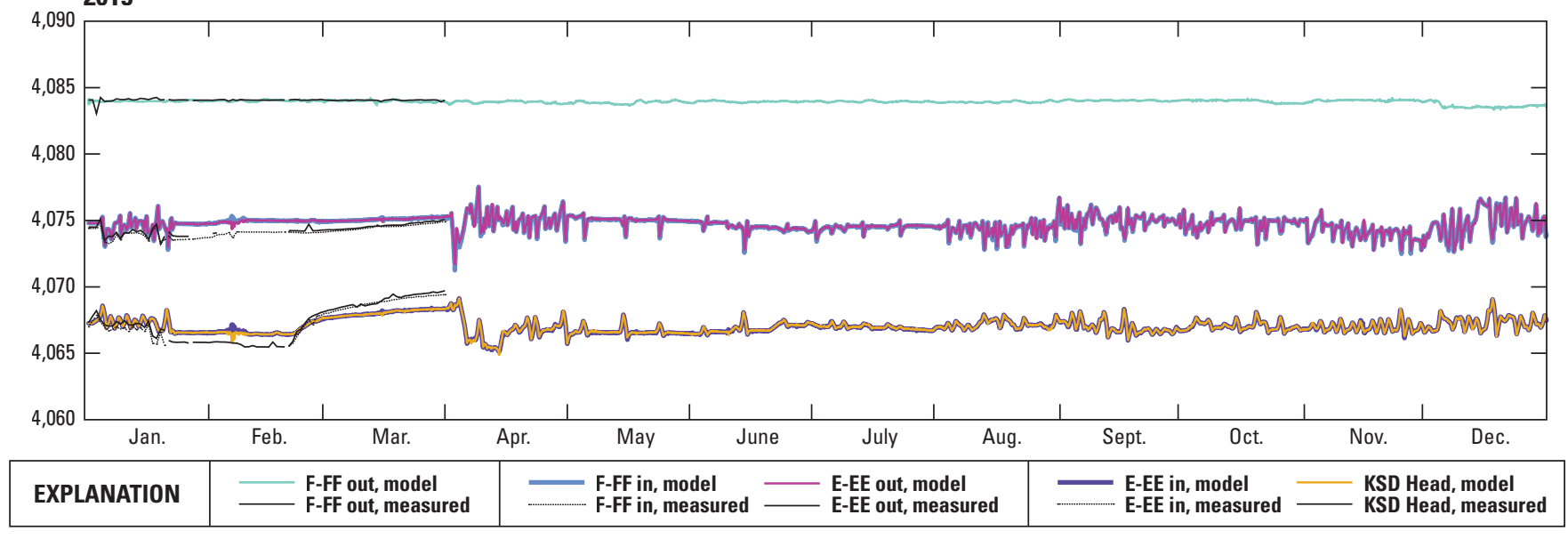

Figure 3. Daily water-surface elevation in Klamath Straits Drain, Upper Klamath River and Lost River Basins, Oregon and California, 2012-15. Measured and modeled data are plotted at the same locations: F-FF pump discharge (F-FF out), F-FF pump sump (F-FF in) and E-EE pump discharge (E-EE out), and the E-EE pump sump (E-EE in) and Klamath Straits Drain Headworks discharge (KSD Head). 
Flow

Flow through the Klamath Straits Drain was largely controlled by pumping. Pumps turned on and off automatically to keep water-surface elevations in the Klamath Straits Drain relatively constant. Flows reflected the on/off behavior by pumps in a step fashion that is clearly illustrated in the 10-minute flow data at the USGS streamgage at KSD97 (11509340) downstream of the F-FF pumps (fig. 4).

Flows were often near zero at KSD97 (11509340) when pumps were off. However, minor flow variability occurred even when the pumps were off. This was likely due to flow produced by other factors, such as wind, density currents, and elevation variations in the pooled Link-Keno reach just downstream. Due to the flat-water gradient at this location, flow could be positive (downstream) or negative (upstream) when the pumps were off (fig. 4).

Modeled and measured flow comparisons at the site downstream of the F-FF pumps had good agreement (fig. 4), with a mean error ranging from -0.05 to $-0.14 \mathrm{~m}^{3} / \mathrm{s}$, and a mean absolute error between 0.27 and $0.84 \mathrm{~m}^{3} / \mathrm{s}$ for the 4 calendar years modeled. This comparison was expected to be close because distributed tributaries were used to account for ungaged inflows, groundwater flow, and gage errors. Generally, the water budget was important to constrain and model closely, as the heat budget and water-quality simulations would not be possible if the water budget could not be reasonably simulated.
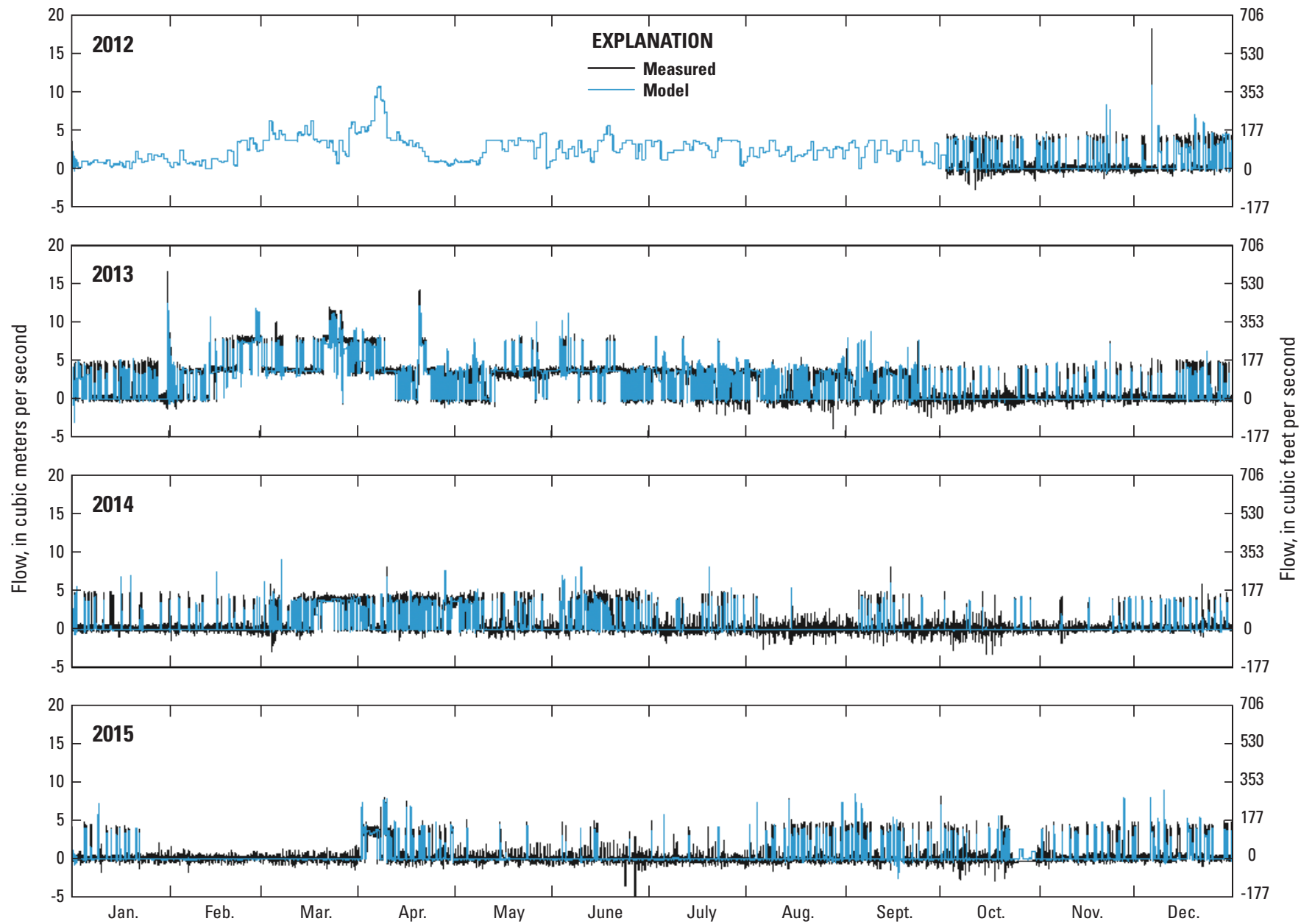

Figure 4. Measured and modeled flow at Klamath Straits Drain at Highway 97, downstream of the F-FF pumps, Oregon and California, calendar years 2012-15. 


\section{Water Velocity}

Acoustic Doppler cross-sectional measurements at KSD97 (fig. 5, top cross-section), downstream of the F-FF pumps showed that when the pumps were on, the velocity across the channel was relatively homogeneous, with most of the flow moving downstream (west, about $270^{\circ}$ ) through the channel profile.

When the pumps were off, far more variability occurred in velocity direction. In a cross section measured at 1500 on March 4, 2015 (fig. 5, bottom), when the pumps had been off for many days, substantial velocity stratification occurred with depth, with the surface waters moving downstream (west, about 270 degrees) and the bottom waters moving upstream (east, about 90 degrees). The model captured this flow variation, showing positive (downstream) velocity nearsurface, and negative (upstream) velocity at depth (fig. 5).

The model can simulate differences in velocity with depth, but as a laterally averaged two-dimensional model, it considers velocity to be homogeneous from bank-to-bank. On February 11, 2014, at 1430 (fig. 5, middle), the F-FF pumps were off, velocities were near 0, and the acoustic Doppler section showed variability in the velocity direction with depth as well as across the channel. Water was moving slowly in the downstream direction on the near-surface part of the north part of the channel, and moving slowly upstream on the south part of the channel and at depth.

Averaged across the KSD97 channel, Klamath Straits Drain water velocity ranged from -0.3 to 1.6 feet per second ( -0.1 to 0.5 meters per second) for the study period. The model simulated the magnitude and temporal variability in water velocity with good agreement (fig. 6). Mean absolute errors in the velocity magnitude ranged from 0.03 to 0.10 feet per second ( 0.01 to 0.03 meters per second) over the 4 model years (table 3$)$.

\section{Water Temperature}

Water temperature in the Klamath Straits Drain had consistent seasonal cycles with coldest winter temperatures (typically below $5{ }^{\circ} \mathrm{C}$ ) in December and January (fig. 7). The warmest water temperatures (greater than $20^{\circ} \mathrm{C}$ ) most commonly occurred from June to August. Weather patterns were superimposed on the annual climate cycle, affecting water temperature on shorter timescales of several days to weeks. The diurnal cycle imposed daily variations in water temperature, producing variations of several degrees, and the largest variations occurred during summer when solar energy fluxes were strongest.

The model simulated Klamath Straits Drain water temperature, with mean errors from -0.4 to $0.1{ }^{\circ} \mathrm{C}$ and mean absolute errors between 0.6 and $0.9^{\circ} \mathrm{C}$ (table 3 ) for 2012-14 (table 3). Mean and mean absolute temperature errors were higher for January 1-March 31, 2015 (table 3), because the model underpredicted water temperature by an average of $1.1{ }^{\circ} \mathrm{C}$ for that period. Generally, daily and weather-imposed variations were captured in the data and model output for Klamath Straits Drain.

\section{Ice Cover}

Ice sometimes covered parts of the Klamath Straits Drain during the coldest periods of the year; therefore, the CE-QUAL-W2 ice-cover subroutine was enabled. As a two-dimensional model, CE-QUAL-W2 cannot simulate ice patchiness across the channel from bank-to-bank. Instead, CE-QUAL-W2 considers the ice to cover the entire surface area of the channel segment. Ice depth in the model varies and changes depending on various factors.

The model generally simulated the presence of ice cover at KSD97 for periods when the field crew also observed ice coverage (fig. 7). However, the field crew noted 0.4-inch ice cover on Klamath Straits Drain 97 on November 18, 2014, that the model did not simulate, although this was a short duration ice event. Field visits surrounding this time on both November 13 and 25, 2014, did not note ice cover.

\section{Total Dissolved Solids and Specific Conductance}

Total dissolved solids (TDS) is a measure of dissolved substances in water, including dissolved nutrients, DOM, and dissolved ions such as carbonate and bicarbonate. The CE-QUAL-W2 model considers TDS to be conservative, so that it is only affected by inflows, outflows, transport, and mixing. TDS is related to specific conductance, which is more commonly measured, as compared to TDS, via continuous monitors. For this study, measured specific conductance was converted to TDS for model usage. Model output TDS was converted to specific conductance for comparison with measurements as described by Sullivan and others (2011). 


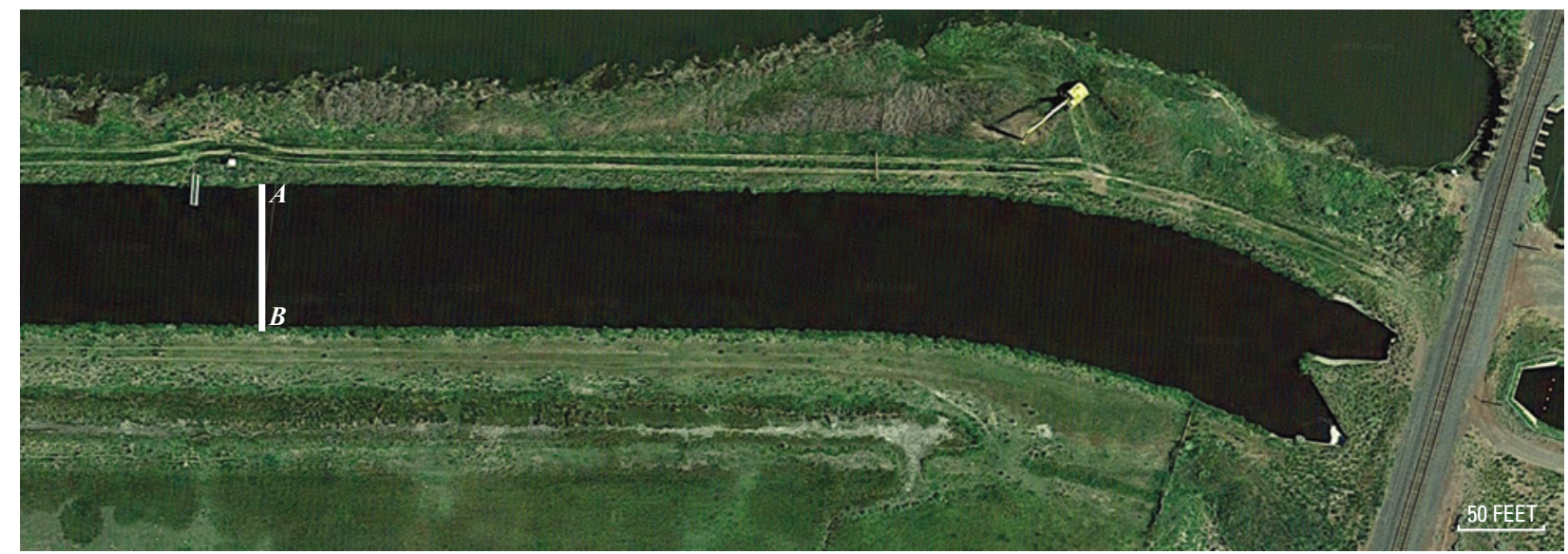

Image from Google Maps, copyright 2018.

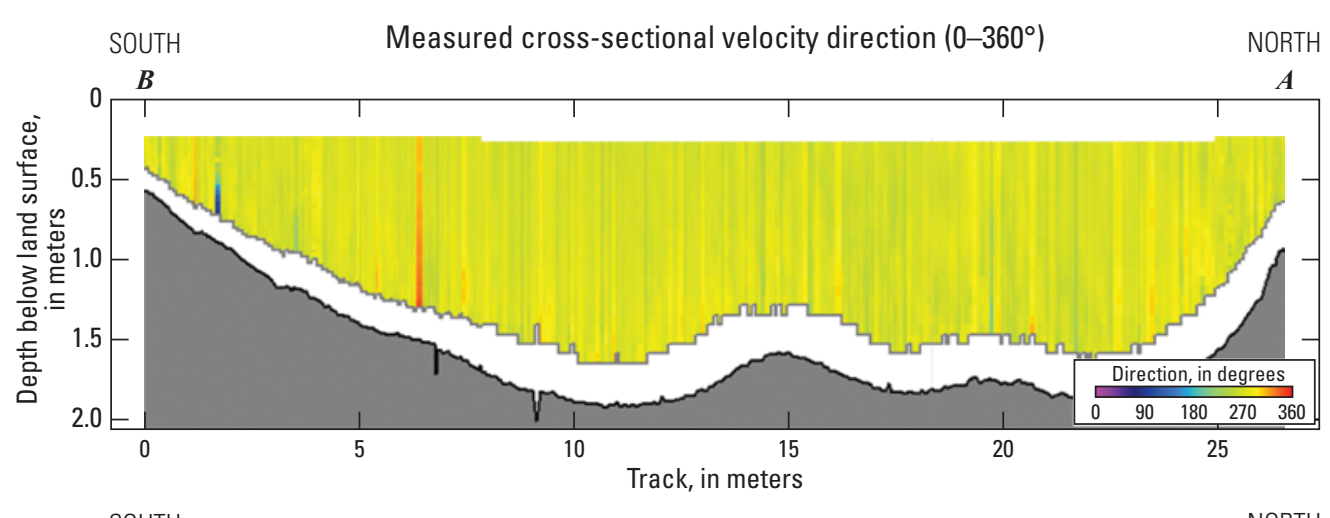

Modeled velocity

Positive $=$ direction $\sim 270^{\circ}$ Negative=direction $\sim 90^{\circ}$
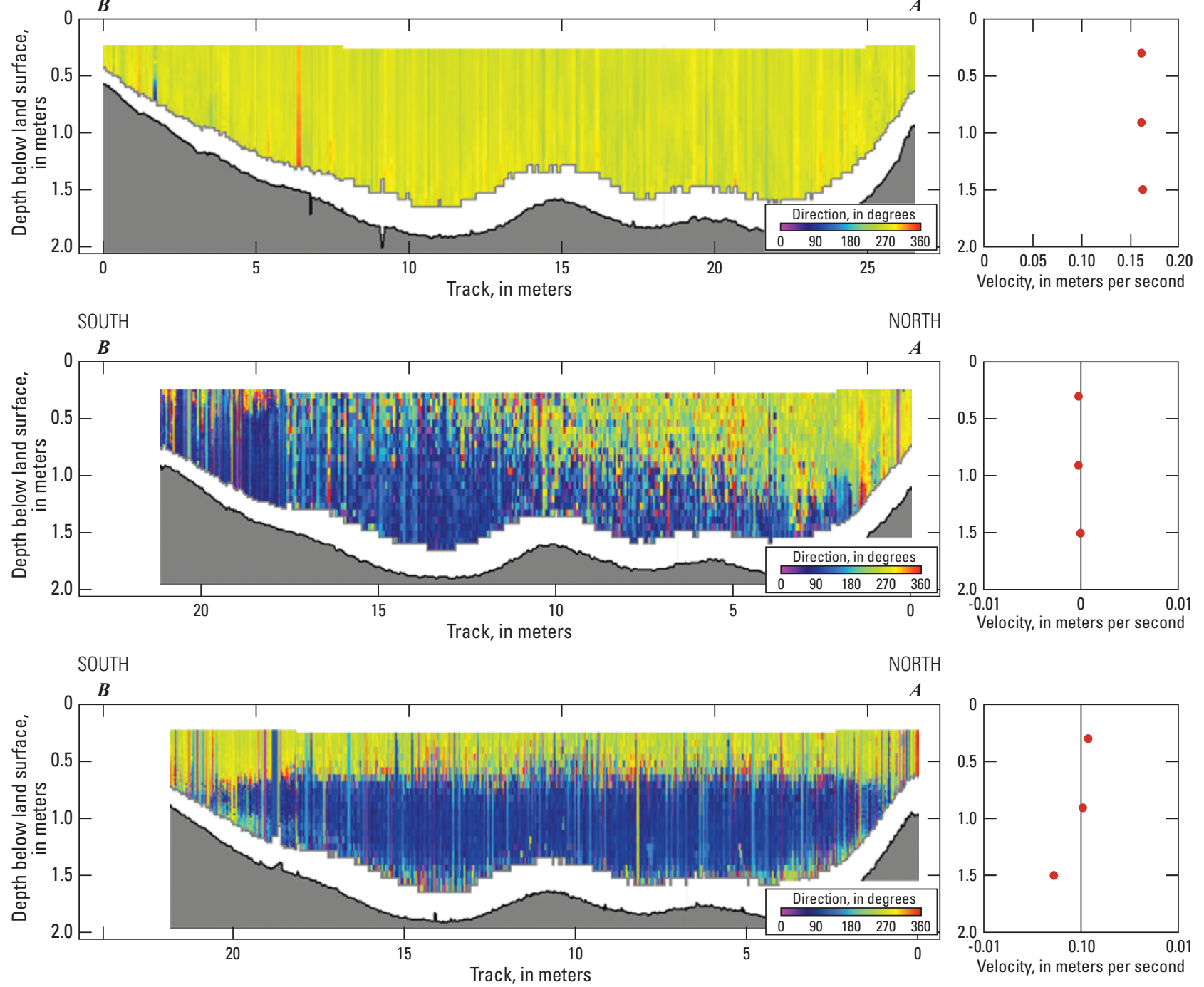

Figure 5. Photograph and cross sections showing velocity direction at Klamath Straits Drain downstream of Highway 97, Oregon and California, 2012-15. Data were collected on (1) April 9, 20141010 with 8.1 cubic meters per second ( $\mathrm{m}^{3} / \mathrm{s}$ ) (286 cubic feet per second [ft3/s]) flow, (2) February 11, 2014, 1,430 with $0 \mathrm{~m}^{3} / \mathrm{s}\left(1 \mathrm{ft}^{3} / \mathrm{s}\right) \mathrm{flow}$, and (3) March 4, 2015, 1,500 with $0 \mathrm{~m}^{3} / \mathrm{s}\left(1 \mathrm{ft}^{3} / \mathrm{s}\right)$ flow. Modeled velocity at three depths for the same date and time, an average across the section for each depth, is also shown to the right of each cross section. Location of cross section $(A-B)$ is shown in the top figure. 

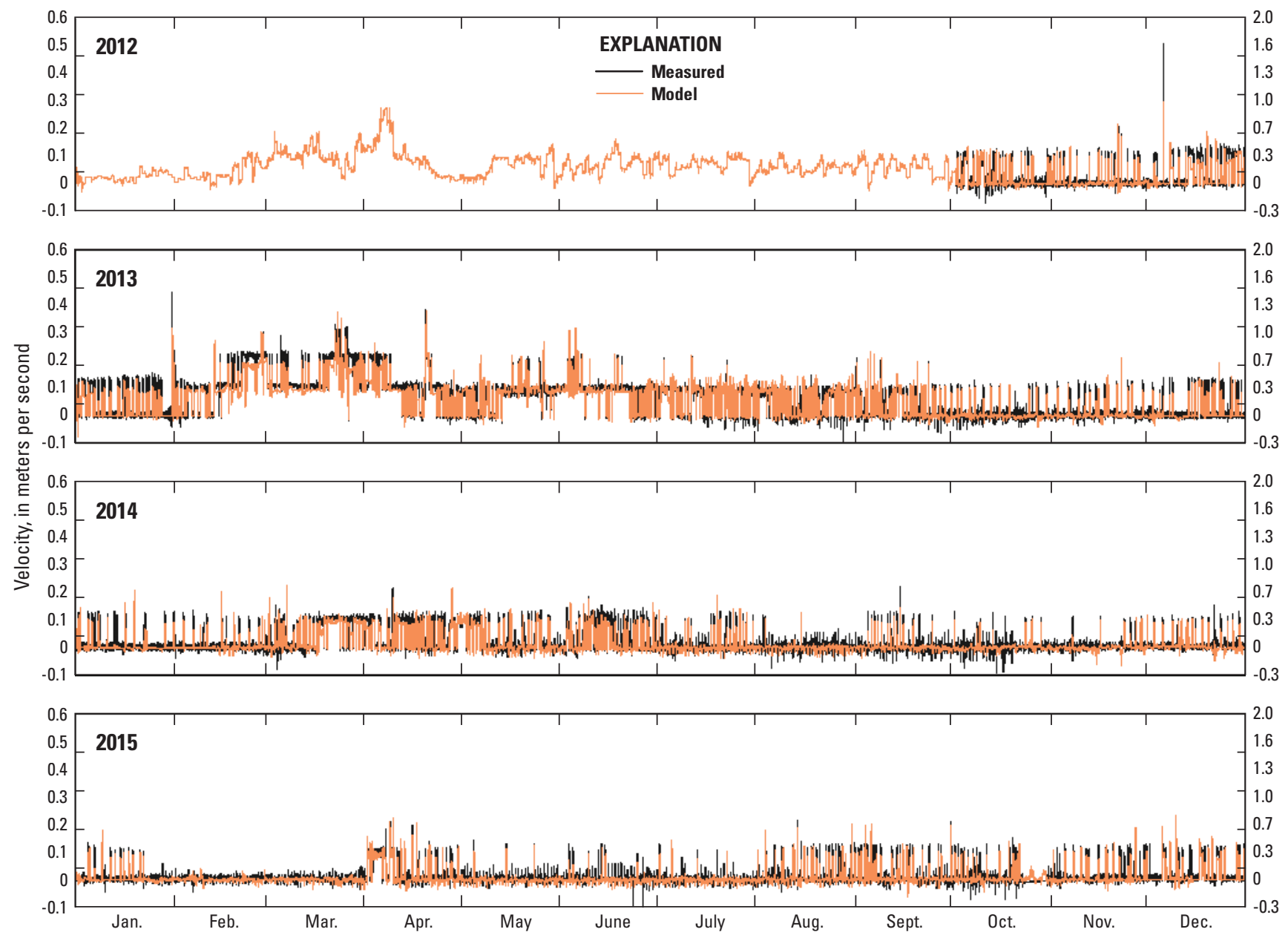

Figure 6. Modeled and measured velocity, Klamath Straits Drain at Highway 97, Oregon, calendar years 2012-15.

Specific conductance measured in Klamath Straits Drain was higher and more variable throughout the year than specific conductance in Klamath River (fig. 8). Klamath Straits Drain specific conductance was typically $250-850(\mu \mathrm{S} / \mathrm{cm})$, with excursions that exceeded $1,000 \mu \mathrm{S} / \mathrm{cm}$ in spring through early summer. Higher specific conductance is likely due to the draining of farm fields and seasonally flooded wetlands. Water interaction with soil typically allows more substances to dissolve and causes the specific conductance to increase. At the Klamath River continuous monitor sites upstream and downstream of the confluence with Klamath Straits Drain, specific conductance was typically $100-200 \mu \mathrm{S} / \mathrm{cm}$ in the years of this study, with some excursions up to $380 \mu \mathrm{S} / \mathrm{cm}$ in winter and spring.

When the F-FF pumps were turned on, the KSD97 site downstream of the F-FF pumps reflected the specific conductance of water in the Klamath Straits Drain upstream of the F-FF pumps. When the pumps were turned off, water from the Klamath River began to mix upstream into the lower part of the Klamath Straits Drain between Highway 97 and the Klamath Straits Drain mouth, resulting in lower specific conductance (and TDS) values.
An example of this mixing occurred August 4-September 15, 2014 (fig. 9). The F-FF pumps were turned on for part of the day on August 4, 2014, then turned off. The KSD97 specific conductance was close to that of the Klamath Straits Drain upstream of the F-FF pumps. The specific conductance gradually decreased after the pumps were turned off, indicating that mixing with the lower specific conductance Klamath River water was occurring. On August 14, the F-FF pumps were turned on for part of the day and the specific conductance showed a sharp increase, indicating upstream Klamath Straits Drain water brought in downstream of Highway 97 by the F-FF pumps. The pumps were then turned off until September 4. During that period, the specific conductance showed a gradual decrease, indicating more mixing with the Klamath River. On September 4, when the pumps were turned on, the specific conductance showed an abrupt increase, indicating the arrival of high conductance Klamath Straits Drain water. 
Table 3. Goodness-of-fit statistics for site KSD97, comparing measured data to model results at the same date and time.

[Year: For water temperature and water quality, 2012 refers to April 1-December 31, 2012; 2015 refers to January 1-March 31, 2015. Flow and velocity statistics were calculated for full calendar years, including 2012 and 2015 . Abbreviations: $\mathrm{m}^{3} / \mathrm{s}$, cubic meter per second; m/s, meter per second; ${ }^{\circ} \mathrm{C}$, degrees Celsius; mg/L, milligram per liter]

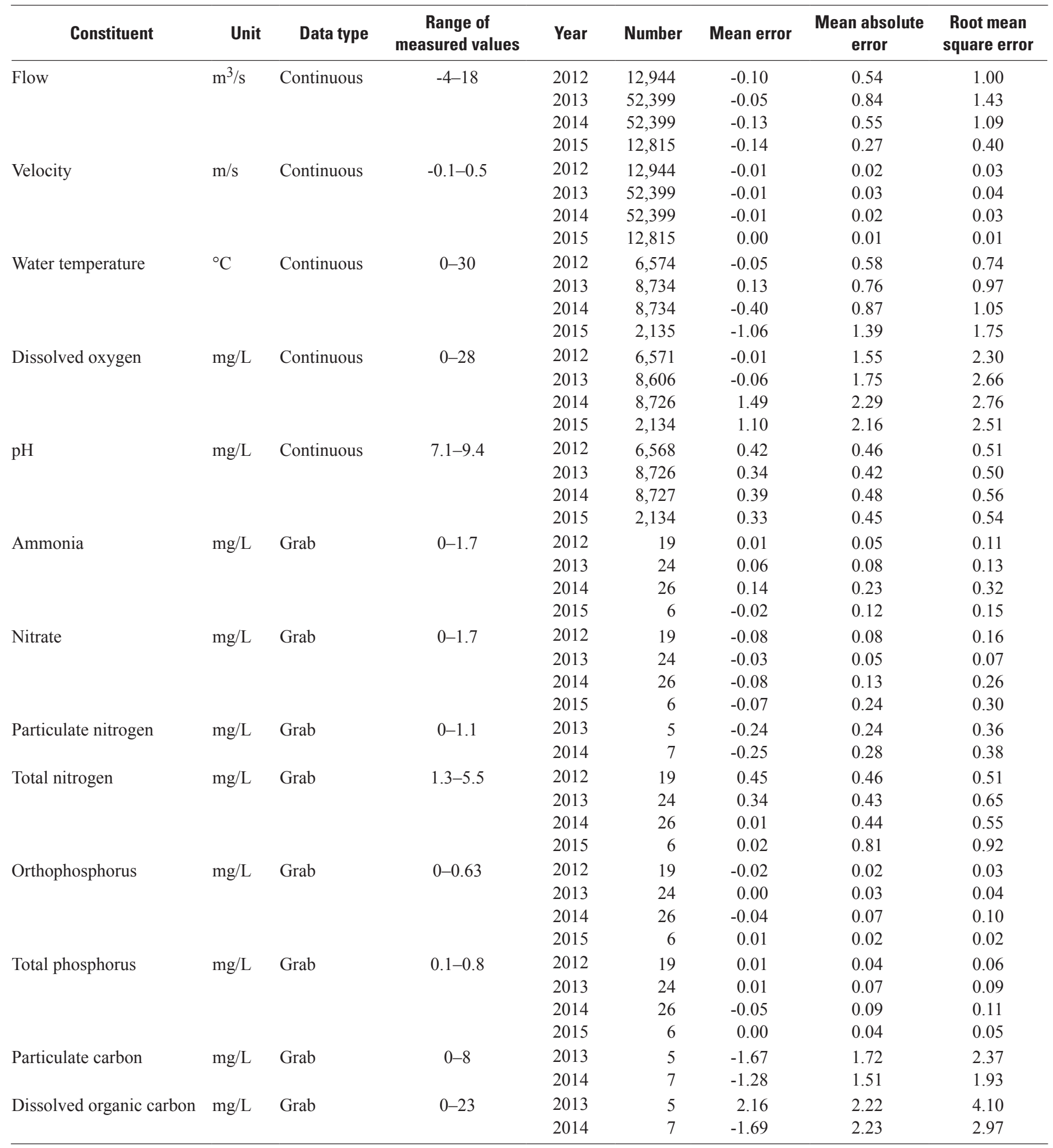


2012
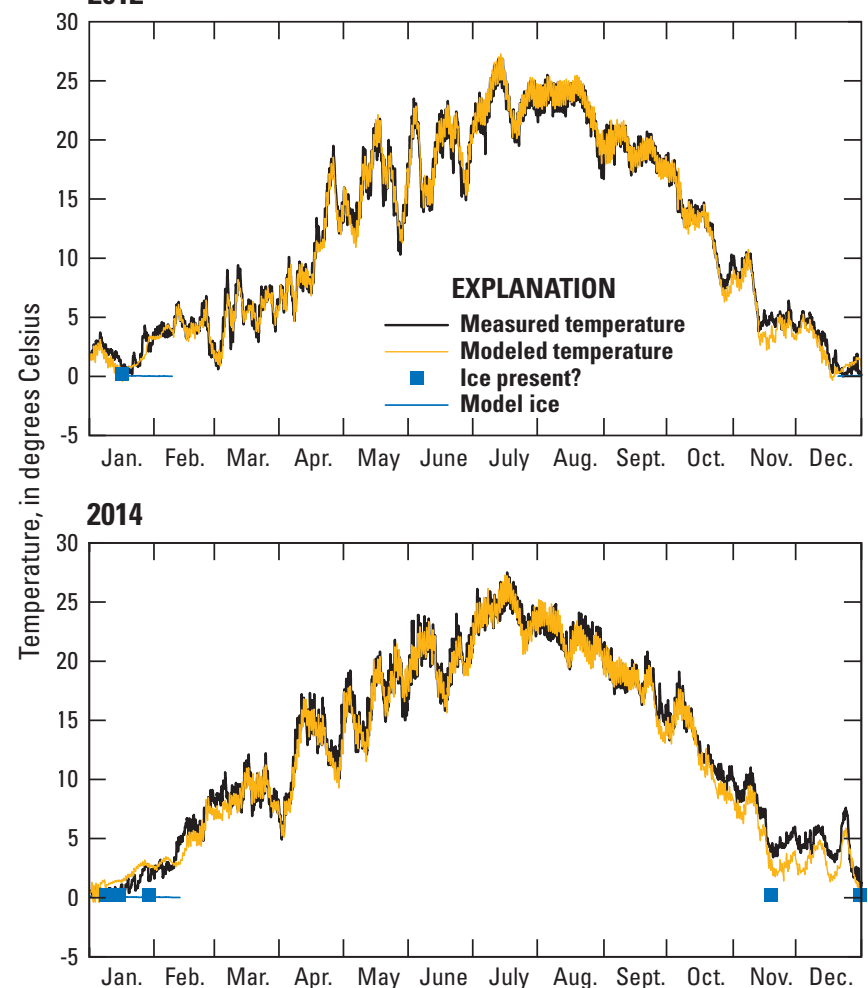

2013

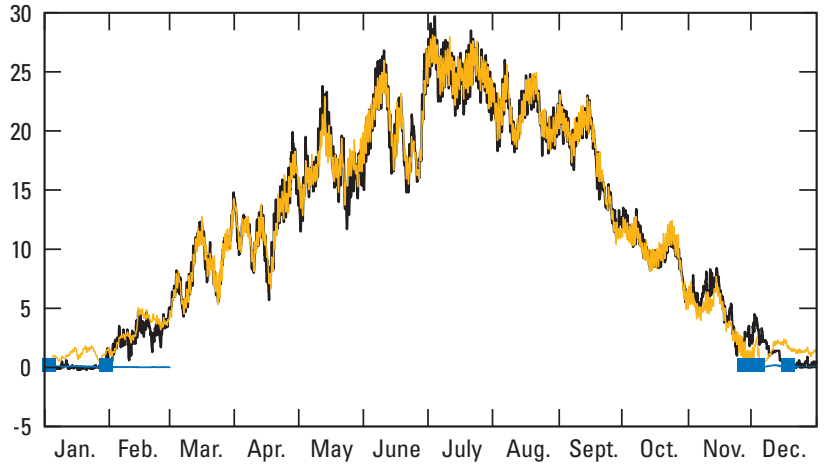

2015

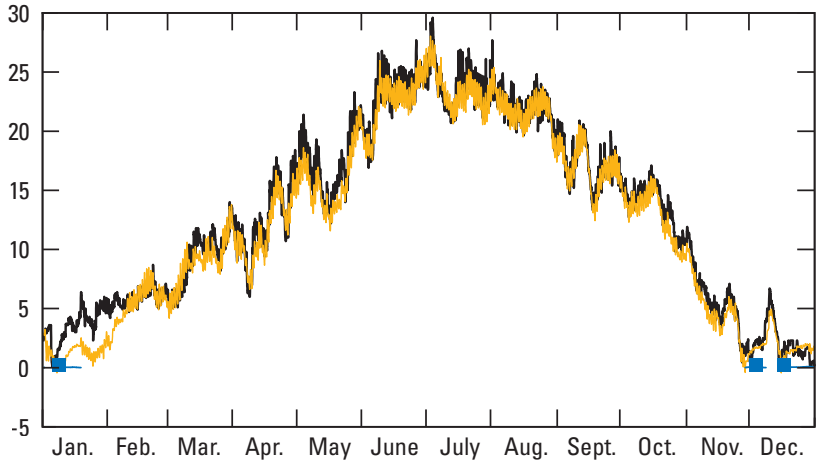

Figure 7. Measured and modeled water temperature, Klamath Straits Drain at Highway 97, Oregon, calendar years 2012-15. Periods with modeled ice cover and dates when the field crew noted ice to be present are shown.

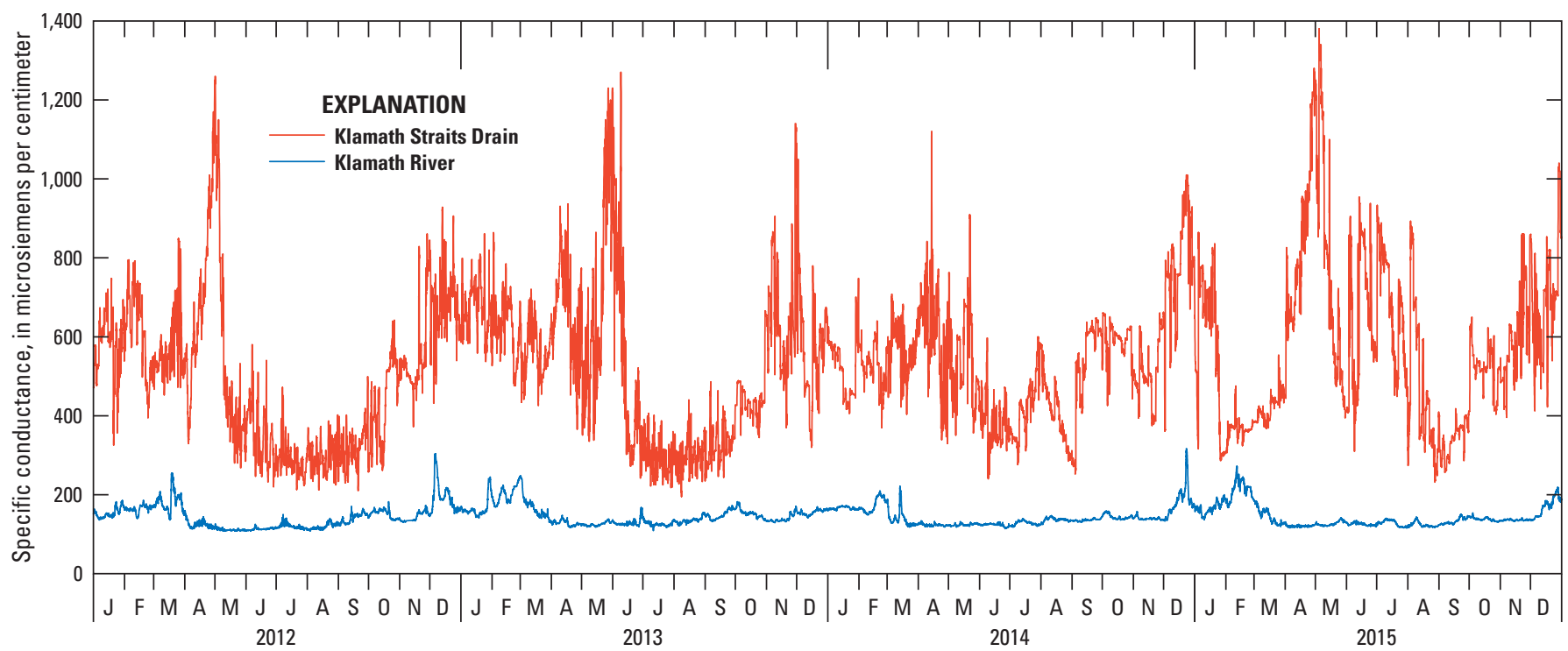

Figure 8. Measured specific conductance at 1-meter depth at sites 420451121510000 Klamath Straits Drain at Highway 97 and 420853121505500 Klamath River at Miller Island, Oregon, 2012-15. 

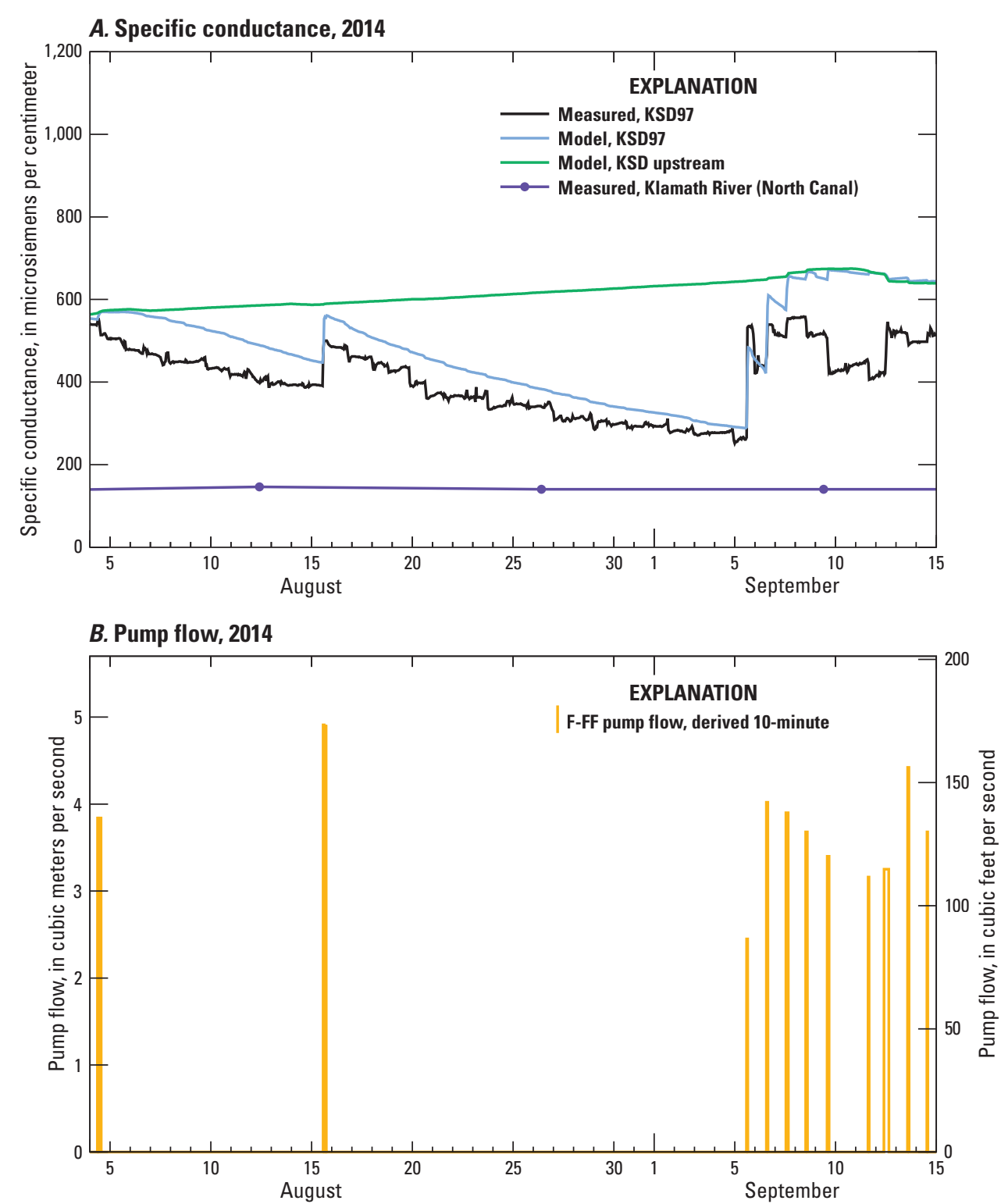

Figure 9. Klamath Straits Drain at Highway 97 modeled and measured specific conductance, modeled specific conductance upstream on the Klamath Straits Drain, and measured specific conductance downstream on the Klamath River $(A)$, and pump flow at the F-FF pumps $(B)$, August-September 2014. North Canal is a withdrawal from the Klamath River upstream of Klamath Straits Drain and thus used as a proxy for Klamath River specific conductance. Pump flow was derived from daily pump data and 10-minute flow data.

Measured specific conductance depth profiles at KSD97, collected during routine visits to the continuous monitor site, only showed minor vertical stratification at the KSD97 site. In other words, the mixing of Klamath River water to this upstream site was occurring throughout the water column. The model suggested a greater amount of vertical stratification in specific conductance near the mouth of Klamath Straits
Drain when the F-FF pumps were on, with the denser Klamath Straits Drain water lying closer to the channel bottom. The model simulated seasonal patterns in specific conductance at KSD97 and simulated some of the variability at finer temporal scales related to pump operation and mixing with Klamath River waters (fig. 10). 


\section{Chlorophyll a}

Chlorophyll $a$ is the chlorophyll type commonly measured to estimate algae in a waterbody. The function of chlorophyll $a$ is to capture solar energy, which then allows the production of cellular biomass through photosynthesis. Klamath Straits Drain had its highest measured chlorophyll $a$ concentrations in autumn, winter, and spring, with generally lower values in summer. This pattern contrasts with chlorophyll $a$ variability in the Link-Keno reach of the Klamath River, which had its highest chlorophyll $a$ concentration and algal biomass in summer. Samples for algae species identification and biomass estimation were not collected during 2012-15, but such samples were collected in Klamath Straits Drain and Klamath River in 2008. Based on this previous work and the cold temperatures that occurred during the Klamath Straits Drain algal blooms, diatoms likely comprised the major autumn, winter, and spring algal bloom that caused increased chlorophyll $a$ concentrations. Diatoms were blooming at remarkably cold temperatures in the Klamath Straits Drain, often less than $10^{\circ} \mathrm{C}$.

Klamath Straits Drain algal biovolumes were generally lower than those in the Klamath River. Klamath River sites had maximum algal biovolumes of $30,000,000 \mu \mathrm{m}^{3} / \mathrm{mL}$ or more, while Klamath Straits Drain had a maximum of $6,000,000 \mu \mathrm{m}^{3} / \mathrm{mL}$. The Klamath Straits Drain model tracks whether algae are nutrient or light limited, and it showed that Klamath Straits Drain algae typically were light limited. Thus, the high light extinction due to increased DOM concentrations in the Klamath Straits Drain likely contributes, in part, to lower levels of algae compared to Upper Klamath Lake and the Klamath River.

With three algal components (blue-greens, diatoms, and other algae), the model was generally able to simulate seasonal patterns and concentrations of chlorophyll $a$ (fig. 10). Some mismatch occurred between modeled and measured chlorophyll $a$ results, most likely because the modeled diatom group had fixed parameters to describe the temperature dependence of ideal growth and other processes, whereas actual diatoms in the Drain likely exhibit greater variability in their growth rates, temperature preferences, and other parameters specific to those species. CE-QUAL-W2 can include multiple algal groups to describe different species responses, but the available data did not support that level of detail.

\section{Nitrogen and Phosphorus}

Excess nitrogen and phosphorus (fig. 10, 11) can lead to nuisance levels of algae and aquatic plants and can contribute to other water-quality issues. Through a TMDL analysis, total nitrogen and phosphorus concentrations and loads in the Klamath Straits Drain have been determined to be too high and were given load allocations that would require reduction of over 80 percent for both nitrogen and phosphorus (Oregon Department of Environmental Quality, 2017).

Total nitrogen in the Klamath Straits Drain was comprised of nitrogen in dissolved ammonia, dissolved nitrate+nitrite, and in DOM and particulate matter (fig. 10, $12,13)$. Over the study period at KSD97, measured total nitrogen ranged between 1.3 and $5.5 \mathrm{mg} / \mathrm{L}$, with a median concentration of $2.6 \mathrm{mg} / \mathrm{L}$. Most nitrogen was in the fraction that included DOM and particulate matter, with a median concentration of $1.9 \mathrm{mg} / \mathrm{L}$ (calculated from total nitrogen minus ammonia minus nitrate+nitrite). For a subset of those samples, particulate nitrogen was measured directly and could be distinguished from the nitrogen in DOM; for those samples, particulate nitrogen made up a median of 84 percent of the particulate and DOM fraction. Dissolved ammonia (as $\mathrm{N}$ ) had a median concentration of $0.43 \mathrm{mg} / \mathrm{L}$, and dissolved nitrate+nitrite (as $\mathrm{N}$ ) had a median concentration of 0.31 $\mathrm{mg} / \mathrm{L}$. Total nitrogen and the components of total nitrogen components did not show strong seasonal cycles, except for nitrate, which had its lowest concentrations in summer and high concentrations (up to $1.6 \mathrm{mg} / \mathrm{L}$ ) in winter.

The partitioning of measured nitrogen between different species at KSDH (upstream, flowing in from the refuge outflow) and KSD97 (downstream) were generally similar, with most of the nitrogen contained in dissolved organic and particulate nitrogen (figs. 12, 13), with the downstream location having a slightly higher proportion of the dissolved inorganic species. Modeled nitrogen concentrations along the length of Klamath Straits Drain showed minor spatial (longitudinal, vertical) variability during most of the year, with some exceptions. Examples of longitudinal variation of dissolved inorganic nutrients are shown in figure 14 for 2013. For example, flow through Klamath Straits Drain was high, and concentrations were similar through the reach on May 1. On May 21, flows were still increased, but the upstream boundary, Klamath Straits Drain Headworks (KSDH), was open and flowing. Headworks flow occurred infrequently in 2013 (fig. 2). An example of mid-summer conditions, with moderate flow, occurred on August 9. On October 18, with the F-FF pumps off for 2 days, the water quality in the most downstream segments was affected by Klamath River water, with nitrate doubling in concentration and ammonia concentration decreasing from the F-FF pumps to the Drain mouth. In a comparison of model output and measured nitrogen data, mean and absolute mean errors were $-0.03-0.08$ and $0.05-0.24 \mathrm{mg} / \mathrm{L}$, respectively, for nitrate; $-0.02-0.14$ and $0.05-0.23 \mathrm{mg} / \mathrm{L}$ for ammonia; $0.02-0.45$ and $0.43-0.81 \mathrm{mg} / \mathrm{L}$ for total nitrogen (table 3). 

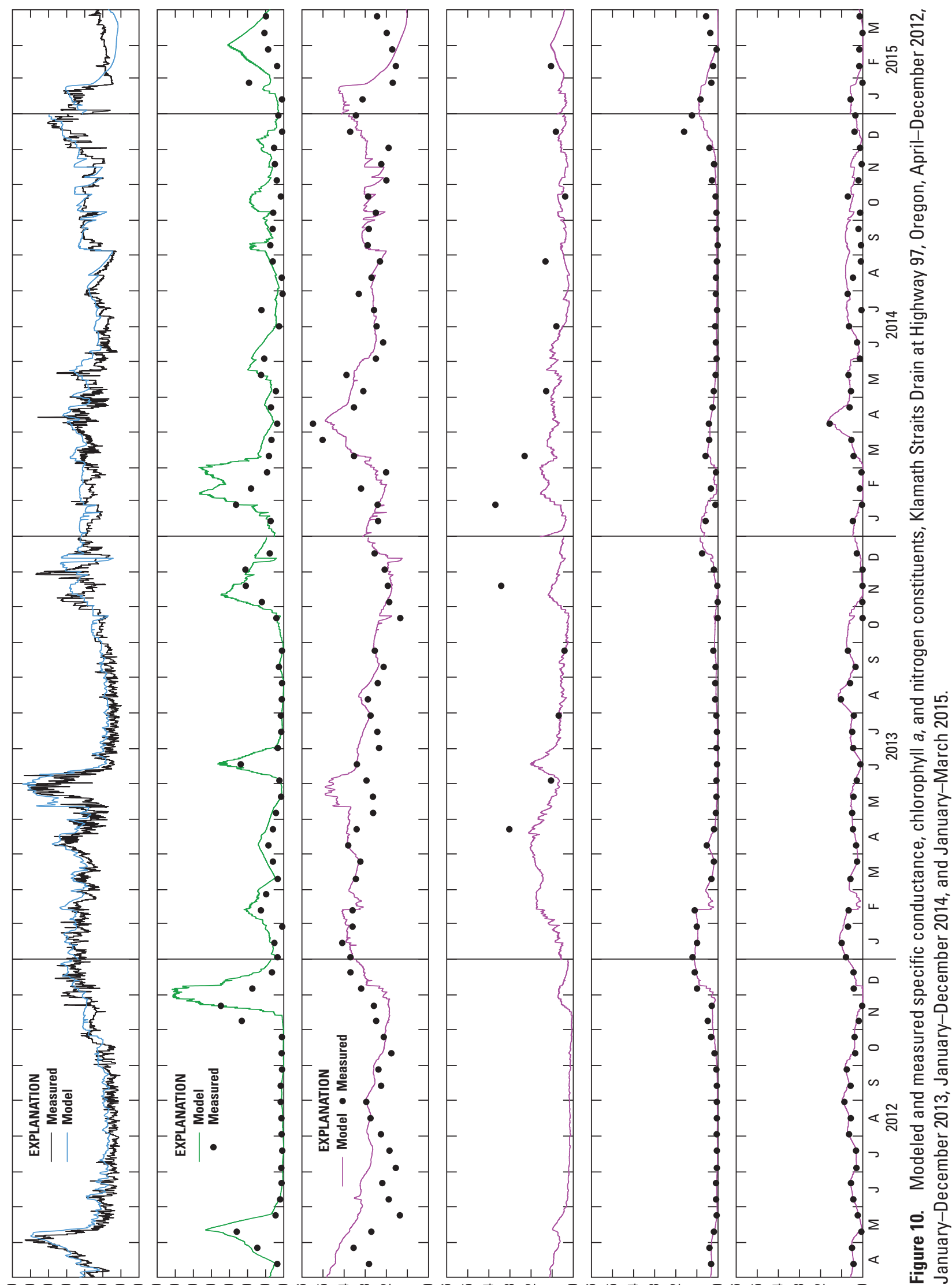

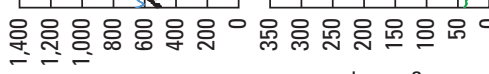

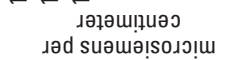

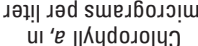

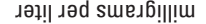
u! 'uә6oג!̣u ןе101 


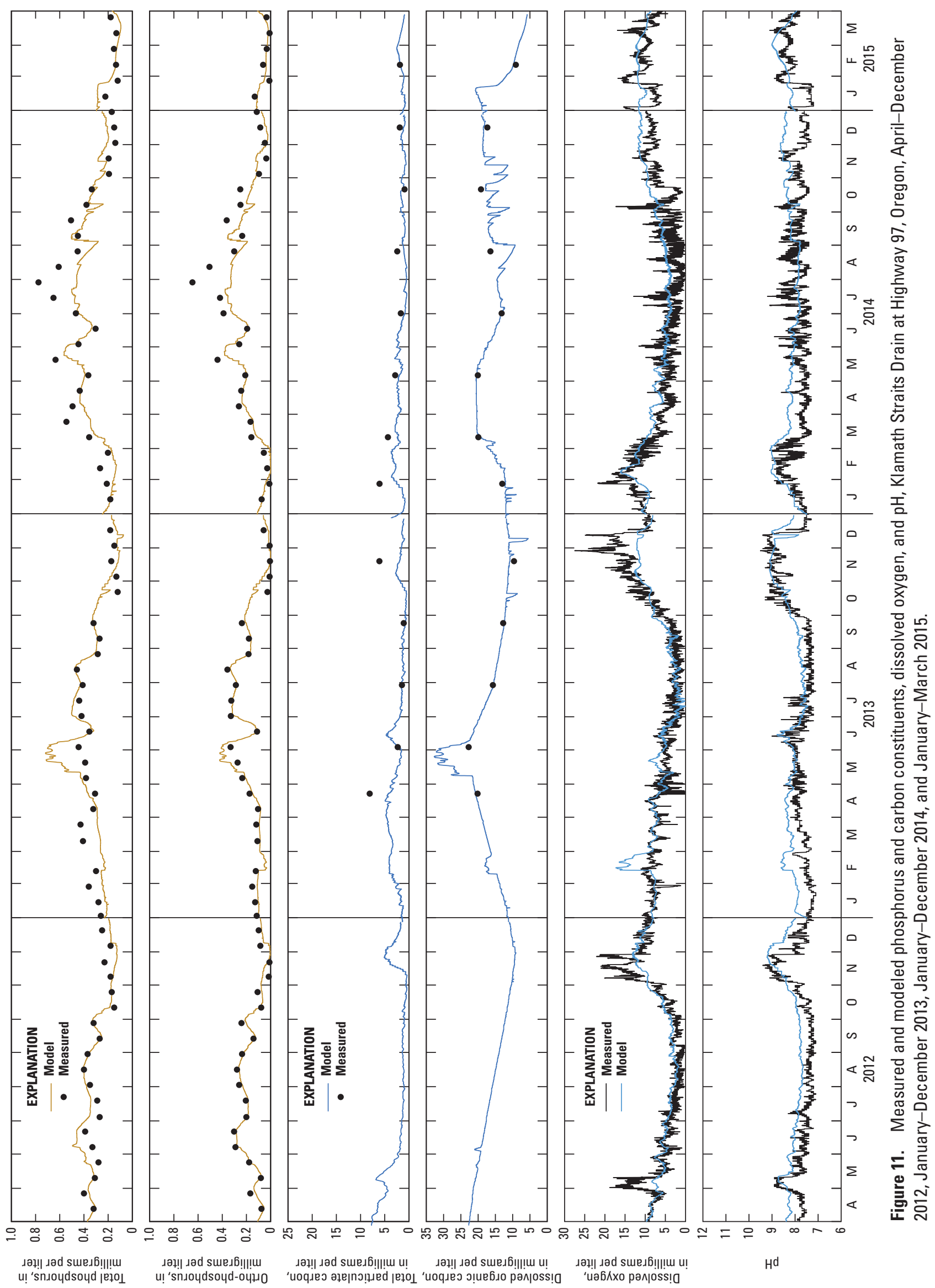



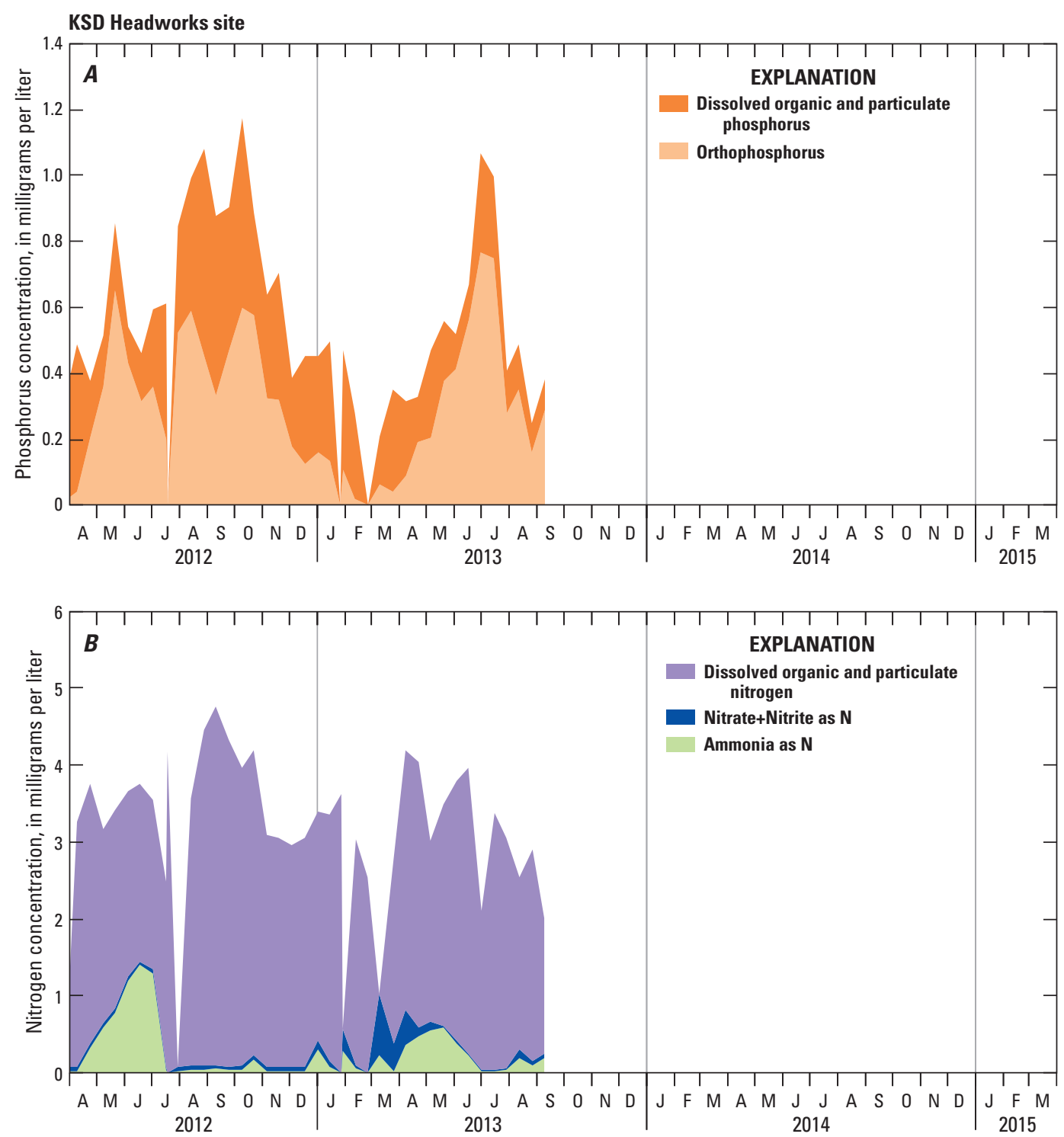

Figure 12. Components of total phosphorus $(A)$ and total nitrogen $(B)$ in Klamath Straits Drain at site Klamath Straits Drain Headworks, Oregon, 2012-15, as determined from measured data. Samples were not collected after summer 2013 because of dry conditions. Flows at this site are shown in figure 2.

Total phosphorus in the Klamath Straits Drain was made up of phosphorus in dissolved ortho-phosphorus, DOM, and particulate matter (figs. 11, 12, 13). Over the study period, at site KSD97, slightly more phosphorus was in the orthophosphorus fraction, with a median concentration of 0.15 $\mathrm{mg} / \mathrm{L}$, although nearly as much was contained in DOM and particulate matter, with a median concentration of $0.13 \mathrm{mg} / \mathrm{L}$. In most years, orthophosphorus concentrations did show seasonal cycles in Klamath Straits Drain, with the highest concentrations typically in summer and lower concentrations in fall and winter.
Despite lower total phosphorus concentrations at KSD97, the proportion of measured phosphorus distributed between different species was similar at KSDH (upstream) and KSD97 (downstream), with slightly more phosphorus in the orthophosphorus fraction at both sites. Modeled orthophosphorus along Klamath Straits Drain's length did not show much variability during most times of the year: exceptions included periods when KSDH was flowing, with higher concentrations at the upstream boundary, and concentration changes near the Drain's mouth when the F-FF pumps were off (fig. 14). 

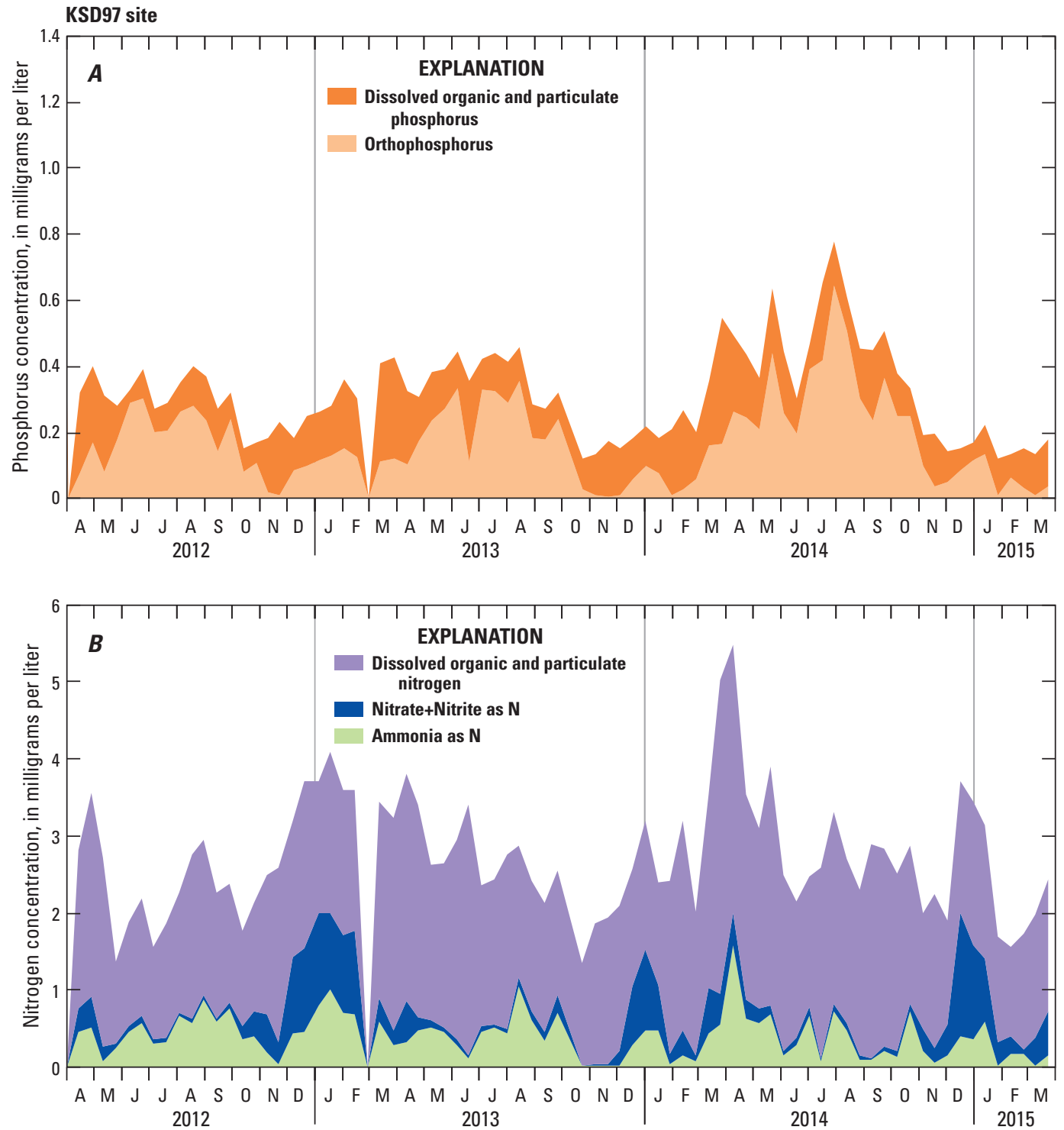

Figure 13. Components of total phosphorus $(A)$ and total nitrogen $(B)$ in Klamath Straits Drain at site Klamath Straits Drain at Highway 97, Klamath Straits Drain Headworks, Oregon and California, 2012-15, as determined from measured data. Flows near this site are shown in figure 2.

Model output revealed that internal kinetic sources of orthophophorus included algal respiration, particulate and dissolved organic matter decay, and from the first and zero-order sediment compartments (fig. 15). The first-order sediment compartment in CE-QUAL-W2 models decay of settled organic matter and algae from the water column. The major internal sink of orthophosphorus was algal growth.

In July and August 2014, the model underpredicted total phosphorus and orthophosphorus concentrations, likely the result of estimated input data. In all the years modeled, mean and absolute mean errors were -0.04-0.01 and 0.02$0.07 \mathrm{mg} / \mathrm{L}$, respectively, for orthophosphorus; mean and absolute mean errors were -0.05-0.01 and 0.04-0.09 mg/L, respectively, for total phosphorus (table 3). The Klamath Straits Drain model simulated the major spatial and temporal patterns in nutrient concentrations and the distribution between the components of total nitrogen and total phosphorus for most of the period of study. 


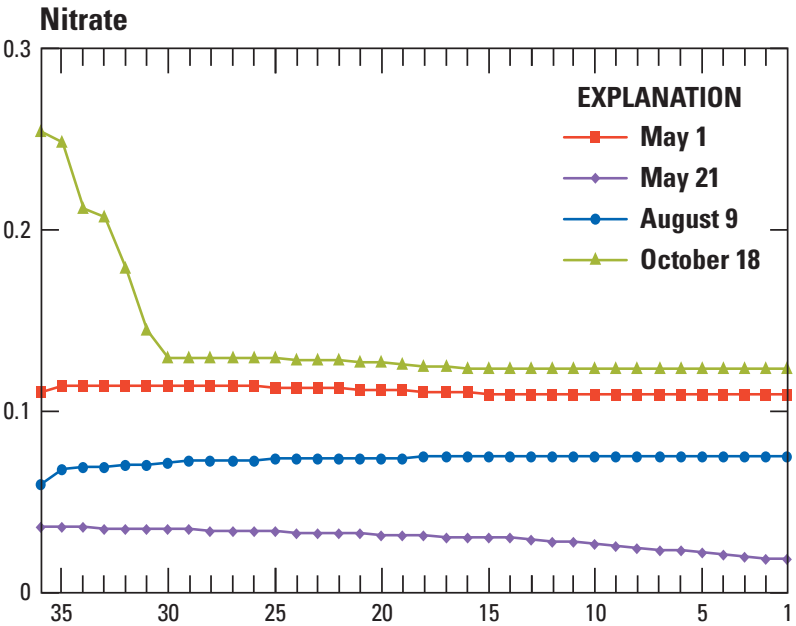

Orthophosphorus

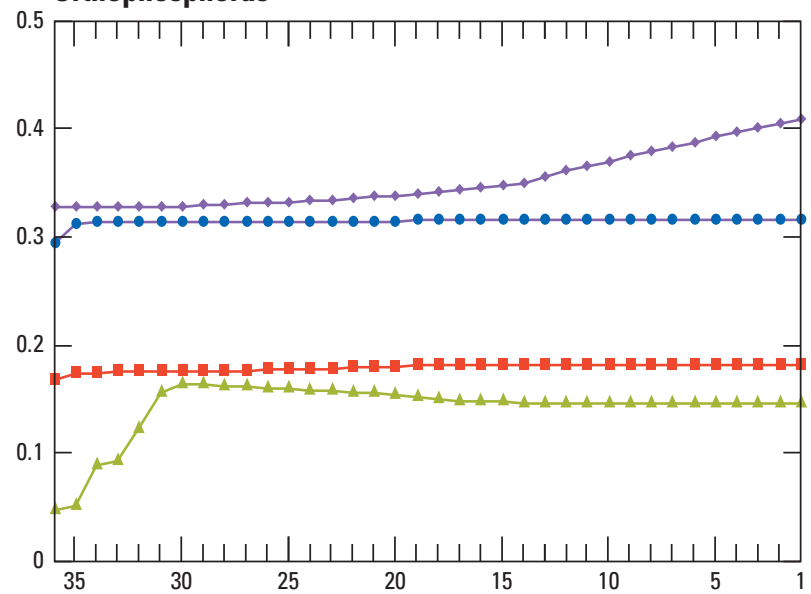

Ammonia

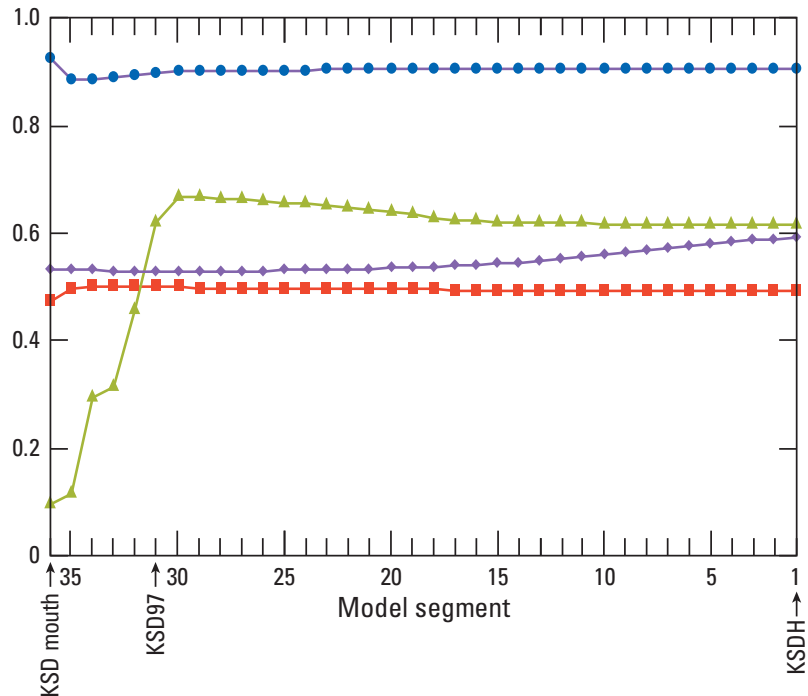

Figure 14. Modeled spatial variation in dissolved inorganic nutrients (nitrate, ammonia, orthophosphorus) along Klamath Straits Drain, Oregon and California, on four selected dates in 2013. KSD mouth, Klamath Straits Drain mouth; KSD97, Klamath Straits Drain at Highway 97; KSDH, Klamath Straits Drain Headworks.

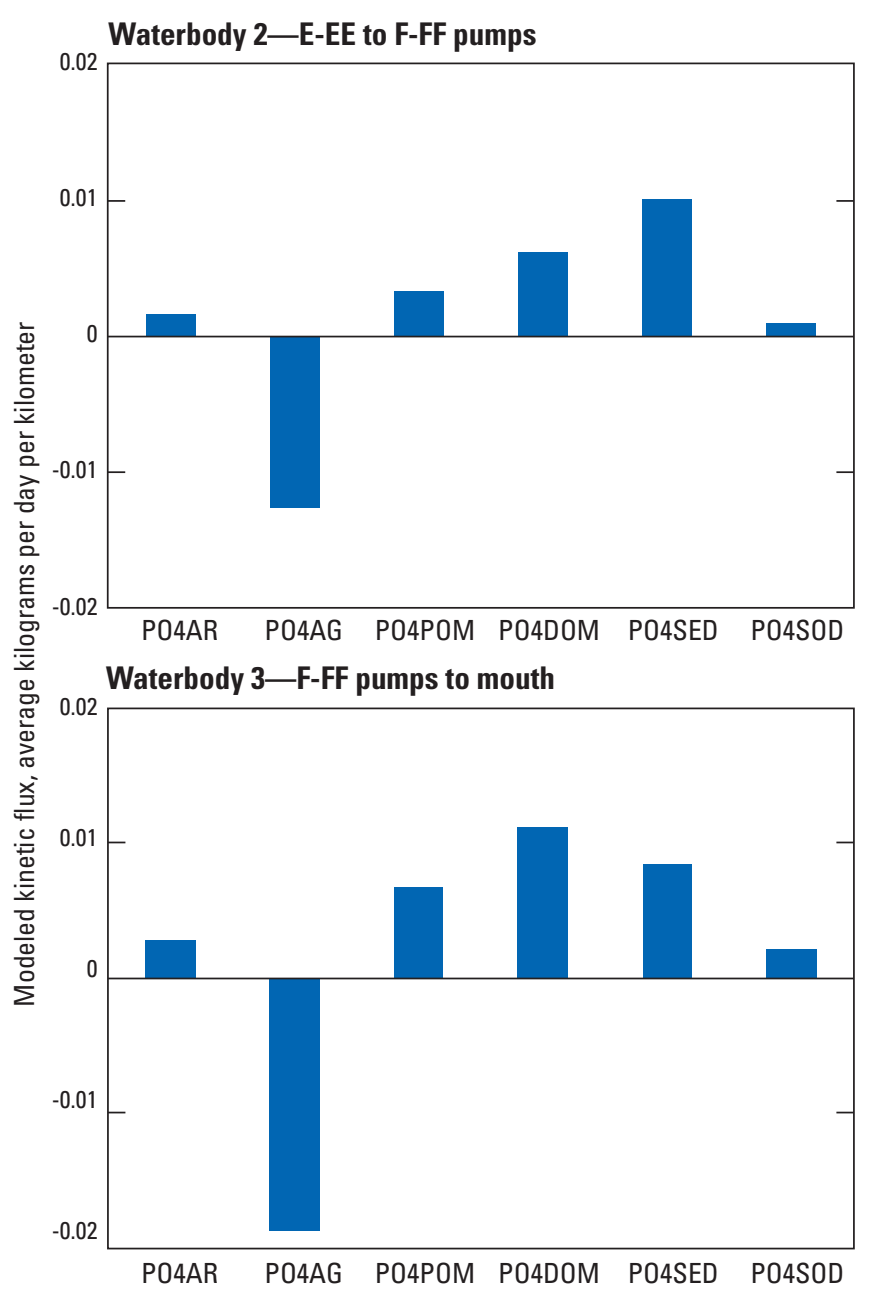

Figure 15. Average modeled internal kinetic fluxes for orthophosphorus $\left(\mathrm{PO}_{4}\right)$ components in waterbody 2, including model segments 15-30, and water body 3 , including segments 31-36 of the Klamath Straits Drain model, Oregon, 2013. P04AR, from algal respiration; $P 04 A G$, into algal growth; P04POM, from particulate organic matter decay; P04DOM, from dissolved organic matter decay; P04SED, from first-order sediment decay; PO4SOD, from zero-order sediment release.

\section{Particulate and Dissolved Organic Carbon}

Along with nitrogen and phosphorus, carbon is an important component of organic matter. The components and characteristics of organic matter in the Klamath Straits Drain, as well as the Lost River and Klamath River, were described in a recent report by Goldman and Sullivan (2017). Together, DOC and POC comprise total organic carbon; these carbon components typically are measured to quantify amount and type of organic matter to aid in understanding nutrient sources, light extinction, and BOD, among other things. Measured DOC at Klamath Straits Drain sites was the largest component of total organic carbon, averaging 18-24 mg/L, with a range of 9-37 mg/L. POC concentrations averaged 3-7 mg/L, with a range of $1-11 \mathrm{mg} / \mathrm{L}$. The DOM was further analyzed 
with fluorescence and absorbance spectroscopy, with results indicating that Klamath Straits Drain samples had increased humification indices that suggested that it was composed of older, highly decomposed and humified organic material. This result is consistent with previous findings (Sullivan and others, 2010, 2011) showing that the DOM from the Klamath Straits Drain typically was composed of more refractory material that would decompose more slowly.

The Klamath Straits Drain model was able to reproduce the general temporal and spatial patterns in DOC concentrations, with mean absolute error of $2.2 \mathrm{mg} / \mathrm{L}$ for 2013-14 (table 3) - the years with more than one measured data point. Particulate carbon was simulated by the model, but underpredicted some of the higher measured concentrations (fig. 11; table 3).

\section{Dissolved Oxygen}

Dissolved oxygen levels are the result of a balance among many processes, including mixing of inflows, oxygen solubility (related to water temperature), atmospheric exchange, algal and macrophyte photosynthesis and respiration, ammonia nitrification, and organic matter decomposition in the water column and sediments.

The importance of these processes in the Klamath Straits Drain varied throughout the year (figs. 11, 16). Oxygen supersaturation due to photosynthesis was most common in the cold months (November-February) due to cold-weather diatom blooms. Dissolved oxygen conditions were lowest in July-September as processes (such as organic matter decay) that consume oxygen became prominent.

Generally, the model was able to simulate general seasonal patterns in dissolved oxygen but was unable to capture all the details. For example, the model was sometimes unable to simulate the highly supersaturated oxygen (up to 200 percent saturation) conditions during winter diatom blooms, and sometimes did not capture the large variability in dissolved oxygen concentrations (fig. 11, year 2014). The oxygen conditions for those winter diatom blooms could likely have been simulated if diatoms were divided into more than one group in the model. In that way, model parameters could be individualized for winter diatom dynamics, rather than applying one set of diatoms for the entire year; however, adding more algal groups generally requires more algal data, which was not available here. Most mismatch in simulation of daily oxygen variability, especially in year 2014, likely is due to uncaptured complexity in algae or localized importance of macrophyte plant photosynthesis.

\section{pH}

Klamath Straits Drain pH ranged from 7.1 to 9.4. Higher $\mathrm{pH}$ levels occurred coincident with algal blooms, which is to be expected because photosynthesis is one of the only mechanisms in this system that can increase the $\mathrm{pH}$ (by taking up carbonic acid to build biomass). The version of CE-QUAL-W2 used in this study had the enhanced $\mathrm{pH}$ buffering subroutine enabled, which allowed the $\mathrm{pH}$ to be affected by the acid-base properties of DOM, ammonia, and phosphates (Sullivan, Rounds, and others, 2013).

Despite the enhanced $\mathrm{pH}$ buffering subroutine, the predicted $\mathrm{pH}$ only partially captures the patterns in the measured data (fig. 11). Mean error for the 4 years modeled was $0.33-0.42$, and mean absolute error was $0.42-0.48$. Generally, $\mathrm{pH}$ is a difficult parameter to model, and simulation errors for $\mathrm{pH}$ often can be traced directly to corresponding errors in the prediction of chlorophyll $a$ or algal biomass because of the high dependence of $\mathrm{pH}$ on photosynthesis.

\section{Model Limitations and Sensitivity}

Water-quality models like CE-QUAL-W2 are most successful when the modelers have access to large amounts of data that describe the waterbody, its inflows and outflows, and the rates and characteristics of instream water-quality processes. However, every modeling study is subject to data limitations due to practical constraints, and most models fall short of approximating the complexity of real systems. A thorough understanding of these data limitations is useful and can provide guidance for future field or lab studies. For this study, the Klamath Straits Drain model development would be improved with:

- More input data to describe the KSDH-E-EE reach water quality: Sensitivity testing showed that modeled Klamath Straits Drain water quality was sensitive to these model inputs.

- Calibration data in the Klamath Straits Drain between KSDH and Highway 97: Additional data of this type would help to improve the calibration and to refine instream rates and parameters.

- Greater temporal and vertical profile details for water quality in the Klamath River at the mouth of the Klamath Straits Drain: Currently, the Klamath Straits Drain model is not connected to the Klamath River model, so the downstream head boundary condition in the Klamath Straits Drain model relies on measured data in the Klamath River taken at one depth and only at 2-week intervals. However, this limitation will be removed when the Klamath Straits Drain model is connected to Klamath River models in the future.

- More frequent pump data at the E-EE pumps: The model was able to use estimated 10-minute pump data at the F-FF pumps by combining daily mean flow data with 10-minute streamgage flow data, but only daily digital data were available at the E-EE pumps. 


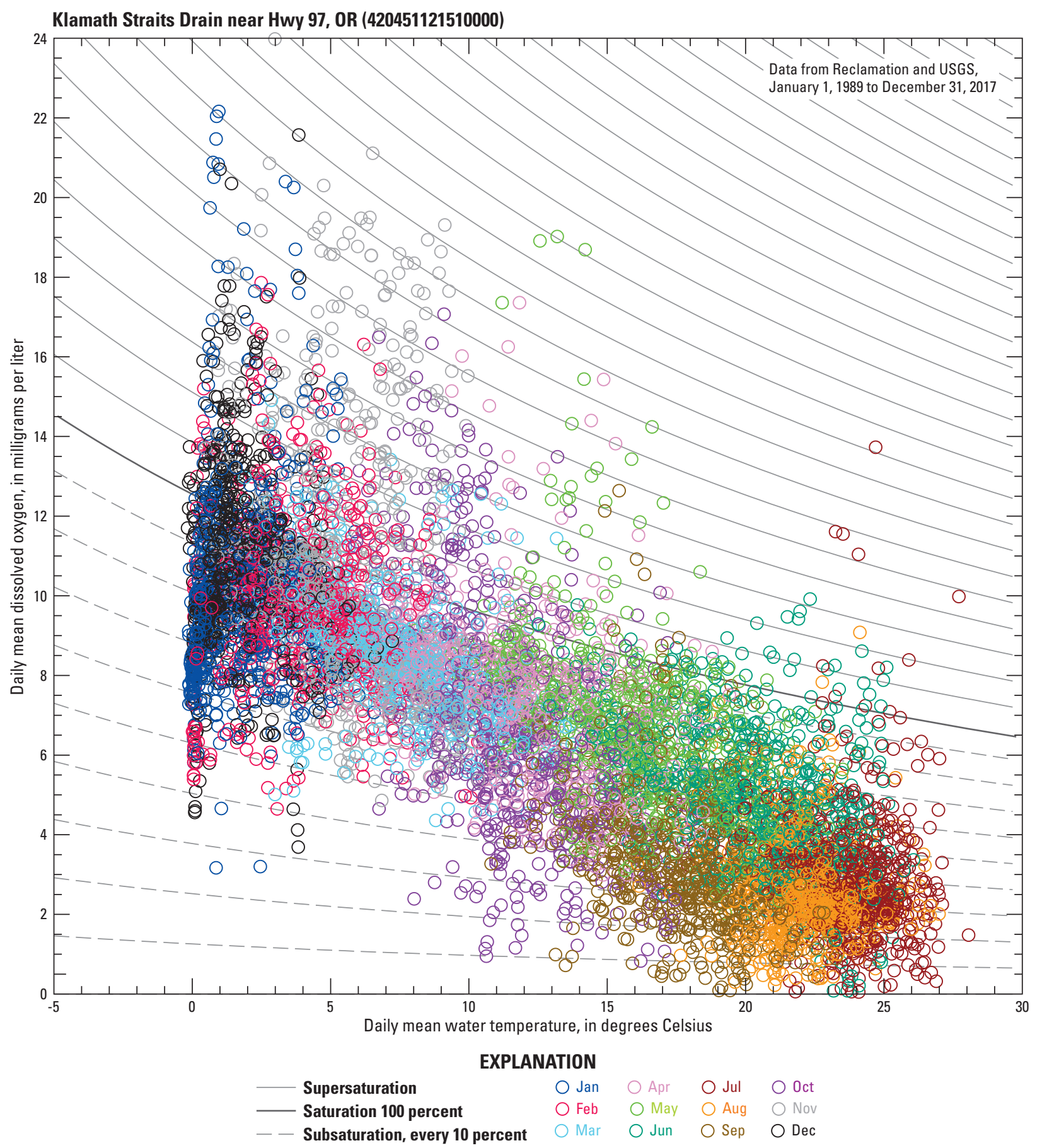

Figure 16. Annual cycle of measured daily mean dissolved oxygen concentrations at Klamath Straits Drain near Highway 97 (site 420451121510000), Oregon, January 1, 1989-December 31, 2017. 
- Better bathymetry for the Klamath Straits Drain downstream of Highway 97: Modeled mixing between the Klamath River and the Klamath Straits Drain was sensitive to the modeled slope and bathymetry and roughness.

- Inclusion of a high-flow year into the model calibration. The Klamath Straits Drain model currently includes normal flow year and dry year conditions.

Despite such data limitations, the model is still useful in providing insights into the patterns and most-important processes driving water quality in the Klamath Straits Drain, as well as insights into how restoration and (or) management activities could affect its flow and water quality. Mechanistic models, even when hampered by a lack of some important data, are still able to provide information about the direction and rate of change in water quality when the system is modified in some way.

\section{Discussion}

\section{Klamath Straits Drain Mixing with Klamath River}

Model results and measured data indicated that mixing between Klamath River and Klamath Straits Drain waters occurred in the reach between Highway 97 (the F-FF pumps) and the Klamath River. This mixing appeared to occur only when the F-FF pumps were off. Thus, in wet or normal hydrologic years, when the pumps were busy and active removing water from the low-lying Lower Klamath Lake area, it is less likely that Klamath Straits Drain sampling results at sites downstream of Highway 97 would have been affected by mixing with Klamath River water. However, in dry years, like years 2013-15 of this study, the pumps can be turned off for many days. The length of time that the pumps are off affected the extent of mixing: while some signs of mixing occurred within the first day of a pump-off condition, the extent of mixing increased over time.

In the 2012 tracer test model run, where tracer was only added to the Klamath River, that tracer was seen in the Klamath Straits Drain on some dates, though mixing was limited to segments nearest the Klamath River (fig. 17). In the segments closer to the F-FF pumps, including those at the KSD97 sampling location, the only tracer observed was a minor amount in November and December. In 2014, the F-FF pumps were off for longer periods, and this appeared to allow mixing through more of the year and farther upstream towards the F-FF pumps.
In the future, it is possible that the F-FF pumps may be off more frequently, even in normal or dry years. More water may be recirculated in the Klamath Straits Drain area, rather than being discharged to the Klamath River. A recirculation project by the Klamath Drainage District has already been implemented, and Reclamation has plans for another potential recirculation project that would help to meet the Klamath Straits Drain TMDL allocation by decreasing exported loads when the pumps are turned off.

The pumps are located and designed such that there is no upstream movement of Klamath River water past the F-FF pumps. Thus, this mixing with the Klamath River is limited to the reach between Highway 97 and the mouth of the Klamath Straits Drain.

\section{Sample Site Location}

The mixing of Klamath Straits Drain and Klamath River waters in the Klamath Straits Drain downstream of Highway 97 has implications for interpreting water-quality results collected at the current Klamath Straits Drain sampling sites downstream of Highway 97. Currently at this location, a water-quality instrument (site 420451121510000) collects hourly water temperature, specific conductance, dissolved oxygen, and $\mathrm{pH}$. This long-term deployment has collected water-quality data, with some gaps, since 1989. Discrete water-quality samples also have been collected downstream of the F-FF pumps as part of USGS (site 420450121504500) and Reclamation sampling programs. The Oregon Department of Environmental Quality sampling site on the Klamath Straits Drain (site 10763) was located upstream of the F-FF pumps.

Mixing of Klamath River and Klamath Straits Drain waters would affect different constituents in different ways. In summer, Klamath River algae are typically more populous, so higher algal concentrations would be present in the Klamath Straits Drain downstream of Highway 97 when mixing occurs. On the other hand, Klamath River DOC concentration was typically lower, so mixing with Klamath River water would lead to lower apparent Klamath Straits Drain DOC concentrations downstream of Highway 97.

To use previously collected Klamath Straits Drain waterquality data, it would be best to have concurrent information on F-FF pump activity or Klamath Straits Drain site 11509340 flow conditions. If flow data were not available, specific conductance data could be used to help interpret how much mixing was occurring, due to the large specific conductance differences between the Klamath Straits Drain and Klamath River. However, that is complicated by the fact that there are many factors affecting specific conductance in Klamath Straits Drain, and the fact that it is so variable (fig. 8). 


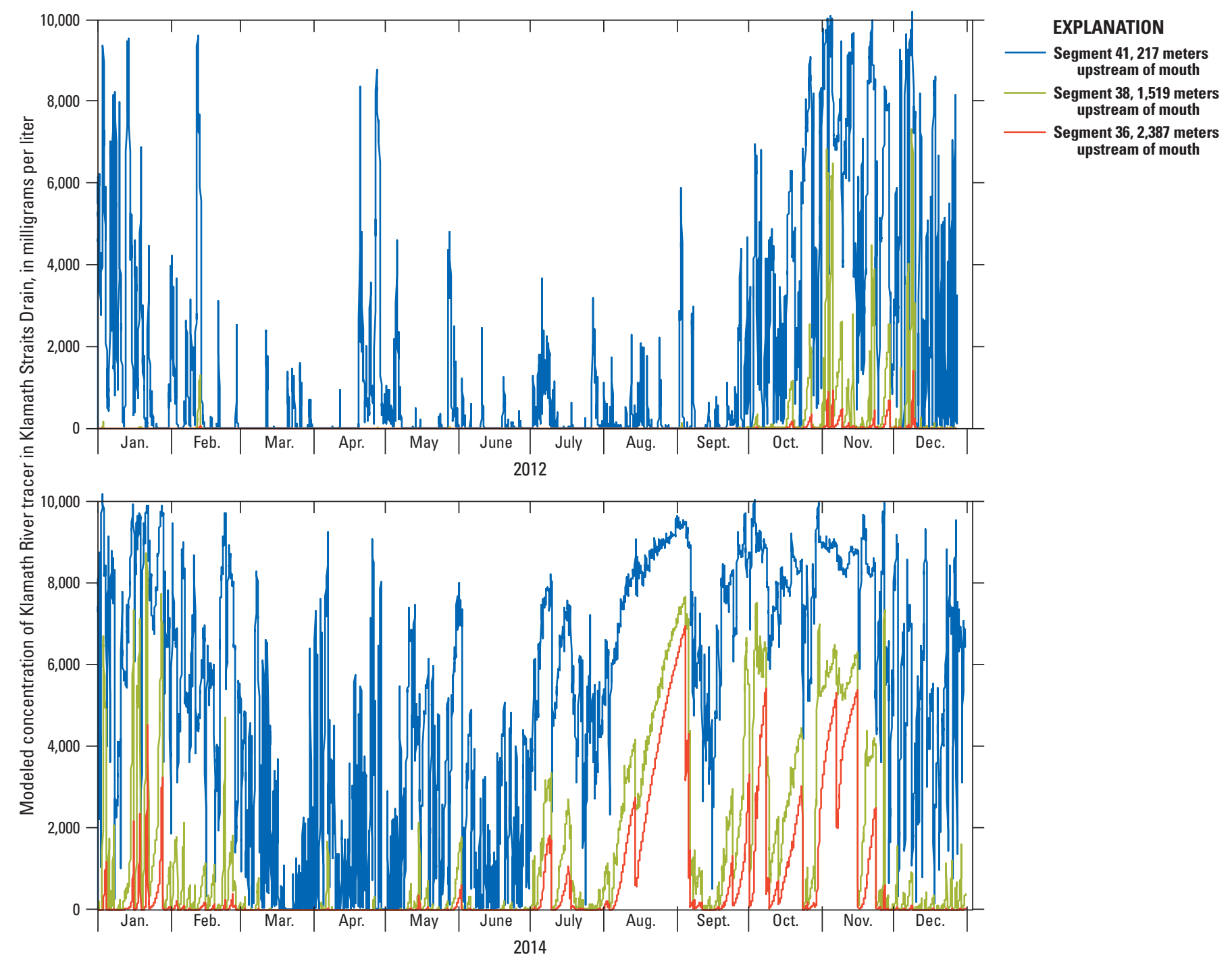

Figure 17. Modeled appearance of Klamath River tracer at locations in Klamath Straits Drain, Oregon and California, in 2012 (normal hydrologic year) and 2014 (a dry hydrologic year). Distance upstream refers to the midpoint location in a model segment.

For future sampling of Klamath Straits Drain waters, a couple of options could be considered. One option would be to move the Klamath Straits Drain sampling site upstream of the F-FF pumps, though this would disrupt the continuity of longterm data sets. Another option would be to keep the current site locations but coordinate between pump operators and water-quality samplers so that the F-FF pumps are turned on when water-quality samples are being taken. This would work for grab samples, but continuous water-quality monitors would still be vulnerable to measuring mixed waters. It is important to know true Klamath Straits Drain water quality to monitor the effectiveness of restoration actions.

\section{Klamath Straits Drain Nutrient Loads}

Model water-quality output reported as loads can provide some insight into how a recirculation project could contribute to Klamath Straits Drain's attainment of TMDL nutrient allocations. A previous modeling study found that when total phosphorus loads were met, total nitrogen and BOD5 loads would also be met (Sullivan and others, 2011). In 2013, average modeled flow at the F-FF pumps was $83 \mathrm{ft}^{3} / \mathrm{s}$. In this year, average modeled total phosphorus concentration at KSD97 was $0.37 \mathrm{mg} / \mathrm{L}$ (average measured total phosphorus was $0.31 \mathrm{mg} / \mathrm{L}$ ) with total phosphorus loads of 164 pounds 
per day (lb/d), significantly higher than the TMDL allocation of $21 \mathrm{lb} / \mathrm{d}$. In 2014, the pumps were on less frequently, and average modeled flow at the F-FF pumps was $23 \mathrm{ft}^{3} / \mathrm{s}$. In this dry year, average modeled total phosphorus concentration was $0.36 \mathrm{mg} / \mathrm{L}$ (average measured total phosphorus was 0.38 $\mathrm{mg} / \mathrm{L}$ ) with loads of $45 \mathrm{lb} / \mathrm{d}$, much closer to the $21 \mathrm{lb} / \mathrm{d}$ TMDL load allocation. Although climate conditions produced those lowered flows to the Klamath River in 2014, engineered solutions to lower Klamath Straits Drain flow to the Klamath River, through recirculation, could move the Drain closer to meeting its nutrient allocation.

\section{Klamath Straits Drain Travel Time}

Under high flow conditions on April 6, 2012, the model tracer was injected at Headworks (KSDH) at noon and reached the end of the Klamath Straits Drain just after 11 a.m. on April 7,2012 . Thus, with flows averaging $374 \mathrm{ft}^{3} / \mathrm{s}\left(10.6 \mathrm{~m}^{3} / \mathrm{s}\right)$, the tracer took approximately 23 hours to flow from $\mathrm{KSDH}$ to the mouth of Klamath Straits Drain.

In contrast, under low-flow conditions on January 1, 2012, the tracer again was injected at noon, and reached the end of Klamath Straits Drain at 3 a.m. on January 12. With the pumps off for part of the time, and flows averaging 32 $\mathrm{ft}^{3} / \mathrm{s}\left(0.9 \mathrm{~m}^{3} / \mathrm{s}\right)$, the tracer took almost 11 days for the peak concentration to reach the Klamath Straits Drain mouth. At low flow conditions on November 10, 2012, the tracer was injected at noon and reached the end of Klamath Straits Drain at 3 p.m. on November 26. Thus, with pumps off for part of the time and flows averaging $14 \mathrm{ft}^{3} / \mathrm{s}\left(0.4 \mathrm{~m}^{3} / \mathrm{s}\right)$, the tracer peak took 16 days to reach the Klamath Straits Drain mouth. Travel time could be greater than 16 days, with pumps turned off for even longer periods. Pumps are needed to create flow in Klamath Straits Drain because the Drain system moves water uphill.

This travel time is estimated for a conservative tracer and is an estimate at different flows, but the actual flow conditions through different parts of the Drain depend on the activity of both pump stations. Substances that settle, undergo chemical reactions, or have nonuniform mixing into the water column would have additional factors affecting their travel times through the Klamath Straits Drain.

\section{Summary and Next Steps}

A hydrodynamic, water-temperature, and water-quality model of the Klamath Straits Drain was constructed and calibrated for calendar years 2012-15. The model was calibrated for water quality for April 1, 2012-March 31, 2015. The model provided insight into transport processes and waterquality conditions and processes in the Klamath Straits Drain, and demonstrated the existence of upstream mixing of Klamath River water into the lower reaches of Klamath Straits Drain.
The next study phase will include the use of the calibrated Klamath Straits Drain model to examine how potential management activities could affect water quality in Klamath Straits Drain and in the Klamath River downstream. Model scenarios could include simulations that examine different alternatives to meet TMDL allocations, modeling the effects of water recirculation within Klamath Straits Drain, and modeling the effects of running Klamath Straits Drain water through constructed or natural wetlands.

\section{Acknowledgments}

Discussions with Rick Carlson, Shane Spiker, and Merlynn Bender of Reclamation, and with Mike Deas of Watercourse Engineering, Inc., were helpful to this study. Paper records of Klamath Straits Drain pump-flow rates and water-surface elevation data were scanned and shared by Ruth Beggs at Reclamation. Randy Spitzer of USGS collected the ADCP profiles at streamgage 11509340; Roy Wellman of USGS helped access and interpret the ADCP data. The Reclamation and USGS sampling crews are thanked for all their field efforts that provided essential data for this modeling study.

\section{References Cited}

Bureau of Reclamation, 1974, Draft environmental statement_-Proposed Klamath Straits Drain enlargement: Bureau of Reclamation, Klamath Project, 94 p.

Bureau of Reclamation, 2016, AgriMet: Bureau of Reclamation, accessed March 2017 at https:/www.usbr.gov/ pn/agrimet/.

Cahoon, J., 1985, Soil survey of Klamath County, Oregon, southern part: Soil Conservation Service, 269 p.

Cole, T.M., and Wells, S.A., 2016, CE-QUAL-W2-A twodimensional, laterally averaged, hydrodynamic and water quality model (version 4.0): U.S. Army Engineering and Research Development Center, variously paged.

Deas, M.L., and Vaughn, J., 2011, Keno Reservoir particulate study 2008-Technical memorandum: Davis, California, Watercourse Engineering, Inc., Prepared for the Bureau of Reclamation, Klamath Basin Area Office, 38 p.

Eilers, J.M., 2005, Aquatic vegetation in selected sites of the Lost River, OR and CA, in Oregon Department of Environmental Quality, 2017, Upper Klamath and Lost River subbasins TMDL: Oregon Department of Environmental Quality, appendix E, December 2017. 
Goldman, J.H., and Sullivan, A.B., 2017, Characteristics of dissolved organic matter in the Upper Klamath River, Lost River, and Klamath Straits Drain, Oregon and California: U.S. Geological Survey Open File Report 2017-1160, 21 p., https://doi.org/10.3133/ofr20171160.

Klamath Drainage District, 2015, Water management and conservation plan: Klamath Drainage District, revised and updated January 31, 2015, 67 p.

Mayer, T.D., 2005, Water-quality impacts of wetland management in the lower Klamath National Wildlife Refuge, Oregon and California, USA: Wetlands, v. 25 , no. 3, p. 697-712, https://doi.org/10.1672/02775212(2005)025[0697:WIOWMI]2.0.CO;2.

National Oceanic and Atmospheric Administration, 2018, Climate data online: National Oceanic and Atmospheric Administration, accessed March 2017 at https://www.ncdc. noaa.gov/cdo-web/.

Oregon Department of Environmental Quality, 2017, Upper Klamath and Lost River subbasins TMDL and water quality management plan: Oregon Department of Environmental Quality TMDL Program, accessed January15, 2018, at http://www.oregon.gov/deq/FilterDocs/ UpperKlamathandLostRiverTMDL.pdf.

Poulson, S.R., and Sullivan, A.B., 2010, Assessment of diel chemical and isotopic techniques to investigate biogeochemical cycles in the upper Klamath River, Oregon, USA: Chemical Geology, v. 269, no. 1-2, p. 3-11, https:// doi.org/10.1016/j.chemgeo.2009.05.016.

Rounds, S.A., and Sullivan, A.B., 2013, Review of total maximum daily load models of Lost River and Klamath Straits Drain, Oregon and California: U.S. Geological Survey Open-File Report 2013-1136, 31 p. [Also available at http://pubs.usgs.gov/of/2013/1136/]

Schenk, L.N., Stewart, M.A., and Eldridge, S.L.C., 2018, Nutrient loads in the Lost River and Klamath River Basins, south-central Oregon and northern California, March 2012-March 2015: U.S. Geological Survey Scientific Investigations Report 2018-5075, 55 p. [Also available at https://doi.org/10.3133/sir20185075.]

Sullivan, A.B., Deas, M.L., Asbill, J., Kirshtein, J.D., Butler, K., Wellman, R.W., Stewart, M.A., and Vaughn, J., 2008, Klamath River water quality and acoustic Doppler current profiler data from Link River Dam to Keno Dam, 2007: U.S. Geological Survey Open-File Report 2008-1185, 25 p. [Also available at http://pubs.usgs.gov/of/2008/1185/.]
Sullivan, A.B., Deas, M.L., Asbill, J., Kirshtein, J.D., Butler, K., and Vaughn, J., 2009, Klamath River water quality data from Link River Dam to Keno Dam, Oregon, 2008: U.S. Geological Survey Open File Report 2009-1105, 25 p. [Also available at http://pubs.usgs.gov/of/2009/1105/.]

Sullivan, A.B., and Rounds, S.A., 2016, Modeling water quality, temperature, and flow in Link River, southcentral Oregon: U.S. Geological Survey Open-File Report 2016-1146, 31 p. [Also available at https://doi.org/10.3133/ ofr20161146.]

Sullivan, A.B., Rounds, S.A., Asbill-Case, J.R., and Deas, M.L., 2013, Macrophyte and $\mathrm{pH}$ buffering updates to the Klamath River water-quality model upstream of Keno Dam, Oregon: U.S. Geological Survey Scientific Investigations Report 2013-5016, 52 p. [Also available at http://pubs.usgs. gov/sir/2013/5016/.]

Sullivan, A.B., Rounds, S.A., Deas, M.L., Asbill, J.R., Wellman, R.E., Stewart, M.A., Johnston, M.W., and Sogutlugil, I.E., 2011, Modeling hydrodynamics, water temperature, and water quality in the Klamath River upstream of Keno Dam, Oregon, 2006-09: U.S. Geological Survey Scientific Investigations Report 2011-5105, 70 p. [Also available at http://pubs.usgs.gov/sir/2011/5105/.]

Sullivan, A.B., Rounds, S.A., Deas, M.L., and Sogutlugil, I.E., 2012, Dissolved oxygen analysis, TMDL model comparison, and particulate matter shunting - Preliminary results from three model scenarios for the Klamath River upstream of Keno Dam, Oregon: U.S. Geological Survey Open-File Report 2012-1101, 30 p. [Also available at http:// pubs.usgs.gov/of/2012/1101.]

Sullivan, A.B., Snyder, D.M., and Rounds, S.A., 2010, Controls on biochemical oxygen demand in the upper Klamath River, Oregon: Chemical Geology, v. 269, no. 1-2, p. 12-21, https://doi.org/10.1016/j.chemgeo.2009.08.007.

Sullivan, A.B., Sogutlugil, I.E., Rounds, S.A., and Deas, M.L., 2013, Modeling the water-quality effects of changes to the Klamath River upstream of Keno Dam, Oregon: U.S. Geological Survey Scientific Investigations Report 2013-5135, 60 p. [Also available at http://pubs.usgs.gov/ $\operatorname{sir} / 2013 / 5135 /$.

Tetra Tech, Inc., 2005, Model configuration and results, Lost River model for TMDL development: Tetra Tech, Inc., Prepared for U.S. Environmental Protection Agency Region 10, U.S. Environmental Protection Agency Region 9, Oregon Department of Environmental Quality, North Coast Regional Water Quality Control Board. 
Publishing support provided by the U.S. Geological Survey Science Publishing Network, Tacoma Publishing Service Center

For more information concerning the research in this report, contact the Director, Oregon Water Science Center

U.S. Geological Survey

2130 SW 5th Avenue

Portland, Oregon 97201

https://www.usgs.gov/centers/or-water 


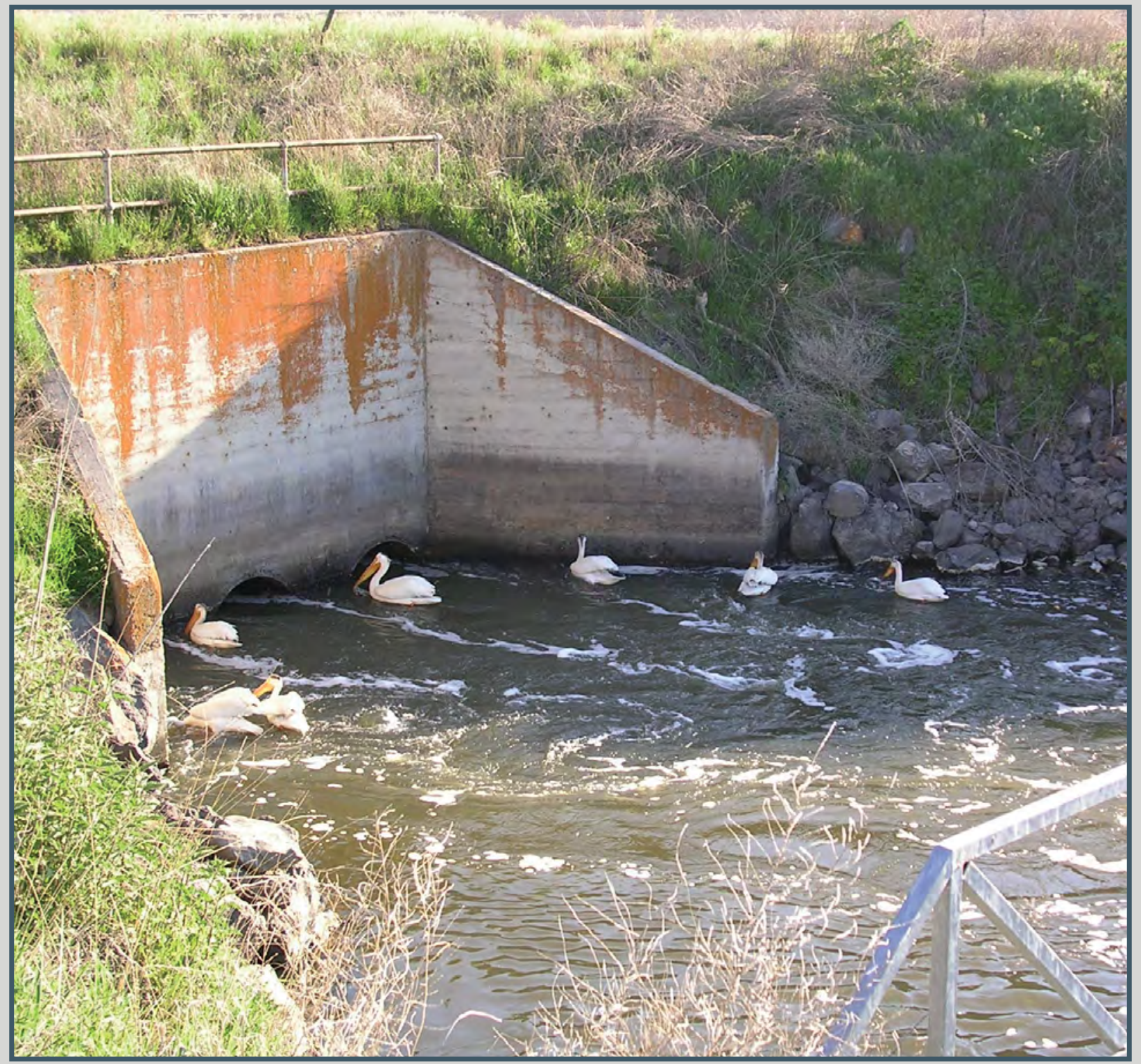

